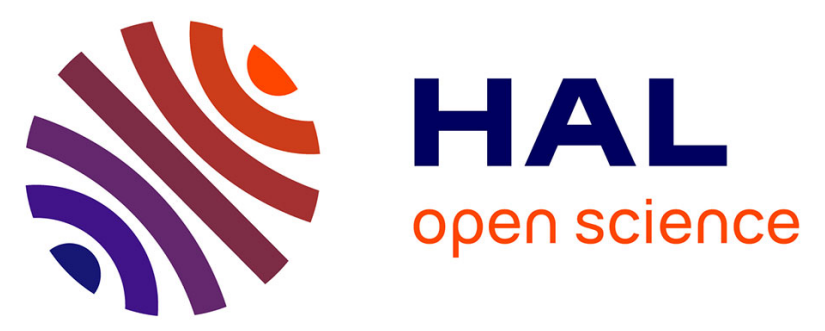

\title{
Effect of reduction on Co catalyst active phase highlighted by an original approach coupling ASAXS and electron tomography
}

S. Humbert, G. Desjouis, T. Bizien, L. Lemaitre, Ahmed Taleb, C. Dalverny, L. Sorbier, A S Gay

\section{To cite this version:}

S. Humbert, G. Desjouis, T. Bizien, L. Lemaitre, Ahmed Taleb, et al.. Effect of reduction on Co catalyst active phase highlighted by an original approach coupling ASAXS and electron tomography. Journal of Catalysis, 2018, 366, pp.202-212. 10.1016/j.jcat.2018.07.024 hal-01980505

\section{HAL Id: hal-01980505 \\ https://hal-ifp.archives-ouvertes.fr/hal-01980505}

Submitted on 14 Jan 2019

HAL is a multi-disciplinary open access archive for the deposit and dissemination of scientific research documents, whether they are published or not. The documents may come from teaching and research institutions in France or abroad, or from public or private research centers.
L'archive ouverte pluridisciplinaire HAL, est destinée au dépôt et à la diffusion de documents scientifiques de niveau recherche, publiés ou non, émanant des établissements d'enseignement et de recherche français ou étrangers, des laboratoires publics ou privés. 


\section{Effect of reduction on Co catalyst active phase highlighted by an original 2 approach coupling ASAXS and electron tomography}

4 S. Humbert $^{\mathrm{a}}$, G. Desjouis ${ }^{\mathrm{a}}$, T. Bizien ${ }^{\mathrm{b}}$, L. Lemaitre ${ }^{\mathrm{a}}$, AL Taleb ${ }^{\mathrm{a}}$, C. Dalverny ${ }^{\mathrm{c}}$, L. Sorbier ${ }^{\mathrm{a}}$, AS Gay ${ }^{\mathrm{a}}$

$5 \quad{ }^{a} I F P$ Energies nouvelles, Rond-point de l'échangeur de Solaize, BP 3, 69360 Solaize, France

$6 \quad{ }^{b}$ SOLEIL Synchrotron, L'Orme des Merisiers, Gif-Sur-Yvette, 91192 Saint-Aubin, France

7 c CT $\mu$, Université Claude Bernard Lyon1,5 rue Raphael Dubois, 69622 Villeurbanne Cedex, France

9 Abstract

10 Diversification of liquid fuel sources for transportation plays a key role in the energetic transition. High 11 quality and clean diesels can be produced by Fischer-Tropsch synthesis, which interest is renewed in as 12 much it can be performed from syngas $\left(\mathrm{CO}+\mathrm{H}_{2}\right)$ produced by conversion of natural gas or gasification of 13 lignocellulosic biomass, leading, in this latter case, to fuels from renewable resource. Catalytic 14 performance (activity and selectivity) of cobalt-based catalysts are related to the physico-chemical 15 characteristics of the cobalt nanoparticles. The present study propose a new approach to obtain a detailed 16 and exhaustive description of the cobalt active phase in FT catalysts. We combined Anomalous Small 17 Xray Scattering (ASAXS) and electron tomography, giving complementary insights on the microstructure 18 and size distribution of both cobalt nanoparticles and aggregates. This approach, carried out on a 19 cobalt/alumina-silica catalysts studied first at the oxide state and then at the reduced state, allowed to 20 highlight the mechanisms involved at the nanoscale during the reduction step. Reduction impact is 21 significant on aggregates morphology, causing their fragmentation and increasing their accessibility. As a 22 perspective, a better knowledge of cobalt aggregates morphology will help to understand their impact on 23 the catalyst performance.

26 Keywords

27 Cobalt, catalyst, Fischer-Tropsch, electron tomography, TEM, ASAXS, nanoparticles 


\section{Introduction}

33 Diversification of liquid fuel sources for transportation plays a key role in the energetic transition.

34 Fischer-Tropsch Synthesis (FTS), initially devoted to convert coal into fuels, has become attractive as it 35 can be performed from syngas $\left(\mathrm{CO}+\mathrm{H}_{2}\right)$ produced by gasification of lignocellulosic biomass, leading, in 36 this latter case, to fuels from renewable resource [1][2]. Low-temperature FTS, based on cobalt catalysts, 37 produces long-chain hydrocarbons leading, after upgrading, to high quality and clean diesels [1][3] [4]. 38 Catalytic performance (activity and selectivity) of Fischer-Tropsch catalysts is related to the physico39 chemical characteristics of the Co nanoparticles. In particular, for all studied supports (carbon nanofibers, $40 \gamma$-alumina), authors observe a rapid increase of the catalytic activity when the cobalt particle size 41 increases to a certain diameter and, then, the activity decreases with further increase in particle size 42 showing a volcano shape curve in catalytic activity. Besides, the $\mathrm{C}_{5}{ }^{+}$selectivity is also known to be 43 related to the size of the nanoparticles and increases while increasing the size of the particles, to circa 44 fifteen nanometers. Depending of the support, the optimal size for higher activity and selectivity is between 6 and $9 \mathrm{~nm}$ [5] [6] [7], smaller particles leading to a significant activity loss. From these results, it is crucial to characterize the nanoparticles, specially their size, which is unlikely to be monodisperse. However, in high-loaded cobalt catalysts (up to $15 \mathrm{wt} \% \mathrm{Co}$ ), the nanoparticles are usually not uniformly dispersed and aggregation of cobalt nanoparticles is often observed, forming aggregates of tens to thousands of nanometers [8] [9]. However, the impact of Co aggregation on activity and selectivity is still unclear / debated. Munnik et al. [8] [9] have observed that the aggregates present in high-loaded catalysts supported on silica were formed during the drying process, after impregnation of aqueous cobalt nitrate precursors. Thus controlling the drying temperature will allow a decrease in aggregate formation rate. By studying catalysts prepared in order to vary the aggregation rate [8], they related an increase of $\mathrm{C}_{5}{ }^{+}$ selectivity with the increase of the aggregates size.

Basing on this literature, it seems essential to characterize both nanoparticle and aggregate scales to fully understand and explain the catalytic performance of the high-loaded cobalt catalysts. For this purpose, a complete description of the active phase implies measuring i) the size distribution of the isolated nanoparticles, ii) the proportion of Co involved in aggregates or in individual particles, iii) the size of the aggregates and iv) the microstructure of aggregates that controls the accessibility of reactant and product within the aggregates. These steps are essential to calculate the intrinsic activity and selectivity and evaluate the impact of aggregation independently to other parameters such as the particles size and the support effect. 
63 Several complementary techniques are commonly used to characterize the Co active phase in FTS 64 catalysts. In particular, Co dispersion is measured by $\mathrm{H}_{2}$ chemisorption, the mean oxide crystallites size is usually measured by X-ray diffraction (XRD) [10] and the particles and aggregates size distribution can be measured by techniques based on transmission electron microscopy (TEM), such as dark-field TEM or 67 HAADF-STEM (high angle annular dark field-scanning transmission electron microscopy) [6,8,9,11]. 68 Concerning the XRD technique, it provides a good evaluation of the average size of the crystallites for the oxide samples, but it is less appropriate for reduced samples as the reduction of the cobalt particles is not total and the peaks corresponding of the $\mathrm{CoO}$ and $\mathrm{Co}^{\circ}$ phase overlap. In addition, the stacking faults present in the cobalt metallic phase lead to a broadening of the peaks not related with the finite size of the crystallites and requires advanced approaches to take them into account, such as Rietveld analysis or pattern simulation of mixture of cubic and intergrown Co [12]. The dark-field TEM also allows size distribution determination of the crystallites but cannot be easily carried out on used catalysts due to the presence of waxes. Furthermore, both XRD and dark-field TEM give information on the crystallites size, which does not correspond to the nanoparticles size if they are polycrystalline. HAADF-STEM can be used to measure Co nanoparticles, but the contrast between Co and the support is usually too low to be sensitive to the smallest nanoparticles.

79 Given the sensitivity of the X-ray scattering phenomenon to the solely electronic density variations, 80 regardless of the structure or size of the crystal domains considered, small-angle X-ray scattering (SAXS) 81 techniques seem particularly suitable to study the size distributions of metal particles on supports. The 82 first work on the characterization of metallic particles on supported catalysts was carried out in the late 1990s by Haubold [13-16] and Benedetti [17,18]. The model systems studied consisted of noble metal particles $(\mathrm{Pt}$ or $\mathrm{Au})$ more or less loaded $(<1 \%$ to $10 \%$ by weight of metal) on graphitic matrix. These systems have significant differences in electronic densities between the support and the metal phase and therefore a significant contrast is obtained in anomalous Small angle X-ray scattering (ASAXS). Polizzi et al. [19] have also proposed a detailed critical analysis of the methodologies selected for these studies, insisting on the need for protocols based on numerous controls of the measurement parameters in order to ensure a good control of the uncertainties, which is essential in the case of ASAXS measurements. The ASAXS technique is nowadays seldom used for the characterization of the active phases of catalysts, even if it is well appropriate for a three-phases system (pores, alumina and cobalt nanoparticles). Moreover, scattering techniques have already proved their possibilities to characterize the size and morphology of aggregates [20]. Hence, this technique has the advantage of being able to characterize 
isolated particles and aggregates of particles. In addition, the analysis can be performed on samples embedded in their waxes, which is very relevant for the case of used FT catalysts.

In order to study the morphology of the aggregates, advanced techniques such as electron tomography can be successfully applied. Based on TEM technique, electron tomography has been developed during the last decades. The principle is to reconstruct a three-dimensional structure from a series of images (or 2D projections) acquired by rotating the sample in the TEM [21] [22]. In the field of heterogeneous catalysis, it was first used to study the shape and the connectivity of mesoporous networks in catalysts supports such as mesostructured silica [23][24] or zeolites [25][26][27][28]. Individual or supported nanoparticles can also be characterized by electron tomography: in the first case, the morphology (including faceting) of the particles is sought [23], in the latter case, the location inside the support can be explored. As an example, Zecevic et al examined the location of Pt in USY zeolites crystals, showing the presence of Pt particles inside the microporosity $[29,29,30]$. If the contrast between the nanoparticles and the support is too weak in bright field TEM, chemical sensitive techniques have to be used [21]. EFTEM is mainly employed for characterization of biphasic supports [31] or low Z materials [32]. HAADF-STEM is the preferred technique for supported catalysts [33]. Compared to bright field TEM mode, HAADF-STEM enhances the contrast between the metallic nanoparticles and the oxide support, in as much as the image intensity is proportional to $Z^{1.7}$ [34]. Arslan and al. [35] studied oxide Co aggregates supported on two different alumina supports. They showed a morphology of fully interlocking aggregates/support in the less selective catalyst.

Combining SAXS analysis and electron tomography has also been performed by Gommes et al. [36] on $\mathrm{Cu}$ catalysts supported on ordered porous silica and allowed illustrating the mesoscale distribution of nanoparticles within supports displaying hierarchical porosity. This study has demonstrated the strong interest of coupling these two kinds of techniques and this approach could be extended to Fischer-Tropsch catalysts provided that SAXS is tuned to ASAXS to specifically focus on cobalt particles and aggregates size.

The purpose of the present study is to propose a new approach to characterize the cobalt active phase in FT catalysts. We combined two analytical techniques : ASAXS and electron tomography, giving complementary insights on the microstructure and size distribution of both Co nanoparticles and aggregates. A better knowledge of Co aggregates morphology will help to understand their impact on the catalyst performance. This approach, carried out on a Co/alumina-silica catalysts studied first at the oxide 
state and then at the reduced state, allowed to highlight the mechanisms involved at the nanoscale during 128 the reduction step.

\section{$130 \quad 2$ Experimental section}

\section{$131 \quad 2.1$ Catalyst preparation}

132 For this study, we have chosen to focus on two cobalt-based catalysts. They were prepared on a Siralox 5

133 silica-alumina support by incipient wetness impregnation of a nitrate cobalt solution, to obtain an amount 134 of $15 \mathrm{wt} . \%$ of cobalt. After impregnation, the catalysts were dried and calcined in air at $400^{\circ} \mathrm{C}$. The first 135 sample is the oxide catalyst. The second one is obtained after reduction under pure $\mathrm{H}_{2}$ flow at $400^{\circ} \mathrm{C}$ 136 during 16h. After reduction, the reduced catalyst is divided into two fractions: the first fraction is 137 passivated under air in order to be analyzed by electron microscopy and the second fraction is embedded 138 in waxes in order to prevent the re-oxidation and to be analyzed in ASAXS.

\subsection{Bulk characterization}

141 XRD measurements were performed on the oxide sample on a PANalytical diffractometer. The most 142 intense $\mathrm{Co}_{3} \mathrm{O}_{4}$ line (311) was used to calculate the average $\mathrm{Co}_{3} \mathrm{O}_{4}$ crystallite size with the Scherrer 143 equation. The mean oxide crystallite size was found to be $16.6 \pm 2.0 \mathrm{~nm}$.

144 XANES analysis was also carried out on the reduced sample embedded in waxes on the ROCK beamline 145 of SOLEIL synchrotron to determine the reduction rate, which is the ratio between the $\mathrm{Co}^{\circ}$ content (wt $146 . \%)$ and the total Co content. XANES spectrum were decomposed thanks to reference sample spectrum. It 147 has underlined the fact that the reduced sample was partially reduced, with a reduction rate of $47 \%$ (see supplementary data, figure 1).

\subsection{TEM and HAADF-STEM observations}

151 By bright-field TEM, the contrast between small cobalt nanoparticles and the silica-alumina support is not 152 sufficient to perform precise size measurements. Thus, cobalt particles size was measured by dark field 153 transmission electron microscopy (DF-TEM). Observations were performed using a JEOL 2100F FEG $154 \mathrm{~S} / \mathrm{TEM}$, operated at $200 \mathrm{kV}$. Samples were crushed in ethanol and sonicated. A drop of the suspension was deposited on a $\mathrm{Cu}$ grid covered with a holey carbon membrane. DF-TEM observations are performed using the diffraction spots corresponding respectively to the (311), (660) or (220) planes in $\mathrm{Co}_{3} \mathrm{O}_{4}$ and 
157 (100), (002), (101) or (102) planes in hcp $\mathrm{Co}^{\circ}$. The particles size was measured on a minimum of $200 \mathrm{Co}$ 158 crystallites.

159 Cobalt aggregates were observed and quantified using HAADF-STEM (high angle annular dark field 160 detector in scanning transmission electron microscopy). Before observation, the samples were embedded 161 in an epoxy resin and thin slices (about $70 \mathrm{~nm}$ ) were cut by ultramicrotomy and transferred onto a $\mathrm{Cu}$ grid 162 covered with a holey carbon membrane. Observations were performed using a JEOL 2100F FEG S/TEM, 163 operated at $200 \mathrm{kV}$. The aggregates size was measured on a minimum of 200 aggregates on several 164 catalysts grains.

\subsection{Electron tomography}

167 Electron tomography was performed using a JEOL 2100F FEG S/TEM, operated at $200 \mathrm{kV}$. Samples were prepared as for DF-TEM observations, except that a drop of a gold colloidal suspension was deposited on the grid for further alignment. Images were taken in HAADF-STEM mode, in order to increase the contrast between aggregates and silica-alumina support. Thus, the morphology of the sole aggregate can be visualized without the contribution of the support. Acquisitions were performed using GATAN Digiscan and Digital Micrograph, by rotating the sample inside the microscope over an angular range of $\pm 60^{\circ}$ using a $1^{\circ}$ tilt increment, in equal scheme, which corresponds to 122 pictures for the "oxide sample", and over an angular range of $+69^{\circ}$ to $-67^{\circ}$ using a $2^{\circ}$ tilt increment, in Saxton scheme, which corresponds to 93 pictures for the "reduced sample". Dynamic focus adjustment was used for acquisition of the tilt series. Alignment of the HAADF-STEM tilt series was performed thanks to cross-correlation and gold fiducial markers, 3D reconstruction was realized by filtered backprojection (via etomo in IMOD[37,38,38]). Segmentation based on grey-levels histograms was undertaken using AVIZO $^{\circledR}$ software. To facilitate segmentation, a pre-processing of the reconstructed volume by a "flowing bilateral filter"[39] was performed. This filter smooths homogeneous regions while preserving the edges of the objects. Morphological geodesic operators were applied in order to extract and quantify the porosity inside the aggregates. Co dispersion in the aggregates was calculated by the ratio between the number of voxels at the surface of the aggregate to the total number of voxels in the aggregate.

\subsection{ASAXS analysis}

\subsubsection{Theoretical aspects of ASAXS}


188 For the case of spherical particles with a radius $R$ dispersed in a homogeneous matrix, the scattered 189 intensity is given by:

$$
I(q)=\frac{N_{p}}{V_{s}}\left(n_{p}^{2} f_{p}^{2}-n_{m}^{2} f_{m}^{2}\right) r_{e}^{2} \int_{0}^{\infty} P(R) V(R)^{2} F(q, R)^{2} \Psi(q) d q
$$

192 with $N_{p}$ the number of tparticles, $V_{s}$ the sample volume, $n_{p}$ and $n_{m}$ the number density of the atoms in the 193 particles and in the matrix, $f_{p}$ and $f_{m}$ the atomic form factors and $r_{\mathrm{e}}$ the Thomson radius $\left(r_{\mathrm{e}}=0.28210^{-12}\right.$ $194 \mathrm{~cm})$.

$195 P(R)$ is the size distribution function, $F(q, R)$ is the form factor and $\Psi(q)$ is the structure factor and 196 equals to 1 when the particles are well-dispersed.

198 For the case of metal particles supported on a porous matrix, for instance on silica-alumina support, the 199 simple SAXS analysis (recording at only one energy) is not sufficient to distinguish and to characterize 200 the nanoparticles as the porous support also contributes significantly to the signal because of the 201 scattering of the pores.

202 Hence, to isolate the signal specific of each phase, it is therefore interesting to vary the energy of the 203 incident beam and to perform the measurements near and far the metal (cobalt in our case) absorption 204 edge.

205 It is recalled that the atomic form factor of a species $j$ can be written:

$$
f_{j}(E)=f_{0}+f_{j}^{\prime}(E)+i f_{j}^{\prime \prime}(E)
$$

207 with $f_{0}=Z$, the atomic number

208 The values of $f_{j}^{\prime}(E)$ and $f_{j}^{\prime \prime}(E)$ are indicated in the Table 1 . We can consider that $f_{j}^{\prime \prime}(E)$ does vary 209 significantly only after the absorption edge.

Table 1. Energy-dependent parts of the atomic scattering factor $f$ ' and f” [40,41], near the Co Kedge of absorption (7709 eV).

\begin{tabular}{cccc}
\hline & Energy (eV) & $\mathbf{f}$ & f” \\
\hline $\mathbf{E}_{\mathbf{1}}$ & 7440 & -3.082 & 0.493 \\
$\mathbf{E}_{2}$ & 7648 & -4.744 & 0.470 \\
$\mathbf{E}_{3}$ & 7694 & -6.356 & 0.465 \\
\hline
\end{tabular}


215 Considering a system of particles $\mathrm{p}$ supported on a porous support $\mathrm{s}$ and with air filling the pores, the 216 scattered intensity can be written thanks to the partial structure factors $S_{p p}, S_{s s}$ and $S_{s p}$ described by 217 Binninger et al. [42] as followed :

$$
\langle I(q, E)\rangle=\left|f_{p}(E)\right|^{2} n_{p}^{2} r_{e}^{2} S_{p p}(q)+\left|f_{s}\right|^{2} n_{s}^{2} r_{e}^{2} S_{s s}(q)+2 \Re\left(f_{p}(E) f_{s}^{*}\right) n_{p} n_{p s} r_{e}^{2} S_{s p}(q)
$$

The difference between the intensities measured at two different energies $E_{1}$ et $E_{2}$ leads to :

$$
\begin{gathered}
\left\langle I\left(q, E_{1}\right)\right\rangle-\left\langle I\left(q, E_{2}\right)\right\rangle=n_{p}^{2} r_{e}^{2}\left(\left|f_{p}\left(E_{1}\right)\right|^{2}-\left|f_{p}\left(E_{2}\right)\right|^{2}\right) S_{p p}(q)+2 f_{s}\left(f_{p}\left(E_{1}\right)-f_{p}\left(E_{2}\right)\right) n_{p} n_{s} r_{e}^{2} S_{s p}(q) \\
=2 n_{p} r_{e}^{2}\left(f_{p}\left(E_{1}\right)-f_{p}\left(E_{2}\right)\right) \cdot\left(n_{p} \overline{f_{p}} S_{p p}(q)+n_{s} f_{s} S_{s p}(q)\right) \\
=2 n_{p}^{2} r_{e}^{2} \overline{f_{p}}\left(f_{p}\left(E_{1}\right)-f_{p}\left(E_{2}\right)\right) \cdot\left(S_{p p}+\alpha S_{s p}\right)
\end{gathered}
$$

223 where $\overline{f_{p}}=\frac{f_{p}\left(E_{1}\right)+f_{p}\left(E_{2}\right)}{2}$ is the mean value of $f_{p}(E)$ and $\alpha=\frac{n_{s} f_{s}}{n_{p} \overline{f_{p}}}$

$$
\begin{gathered}
S_{p p}(q)=\frac{N_{p}}{V_{s}} \int_{0}^{+\infty} P_{p}\left(R_{p}\right) V\left(R_{p}\right)^{2} F\left(q, R_{p}\right)^{2} d R_{p} \\
S_{m p}=\frac{N_{p}}{V_{s}} \iint_{0}^{\infty} P_{p}\left(R_{p}\right) P_{S}\left(R_{s}\right) V\left(R_{p}\right) V\left(R_{s}\right) F\left(q, R_{p}\right) F\left(q, R_{s}\right) \frac{\sin \left(q\left(R_{p}+R_{s}\right)\right)}{q\left(R_{p}+R_{s}\right)} d R_{p} d R_{S}
\end{gathered}
$$

As a first approach, we can consider that the term $\alpha S_{s p}$ is negligible before $S_{p p}$ if $\alpha\left\langle\frac{\left\langle V\left(R_{p}\right)^{2}\right\rangle}{\left\langle V\left(R_{p}\right)\right\rangle\left\langle V\left(R_{S}\right)\right\rangle}\right.$.

In our case:

- we have calculated for $E_{1}$ and $E_{2}$ energies, an $\alpha$ close to 0.55

- the size of the pores and of the particles are in the same order of magnitude, so that $\frac{\left\langle V\left(R_{p}\right)^{2}\right\rangle}{\left\langle V\left(R_{p}\right)\right\rangle\left\langle V\left(R_{S}\right)\right\rangle}$ is higher than 1.

It can be concluded that in the present case of the cobalt-based catalysts, the contribution of the supportparticle interaction term is negligible. Indeed, as explained by Morfin et al [10], the particles are big enough and their volume fraction is small compared to the aluminum support consequently the probability of interference between the cobalt particles and the support is low.

It follows :

$$
\left\langle I\left(q, E_{1}\right)\right\rangle-\left\langle I\left(q, E_{2}\right)\right\rangle \approx 2 n_{p}^{2} r_{e}^{2} \overline{f_{p}}\left(f_{p}\left(E_{1}\right)-f_{p}\left(E_{2}\right)\right) . S_{p p}(q)
$$

$$
\left\langle I\left(q, E_{1}\right)\right\rangle-\left\langle I\left(q, E_{2}\right)\right\rangle \approx \frac{N_{p}}{V_{s}} n_{p}^{2} r_{e}^{2}\left(\left|f_{p}\left(E_{1}\right)\right|^{2}-\left|f_{p}\left(E_{2}\right)\right|^{2}\right) \int_{0}^{+\infty} P_{p}\left(R_{p}\right) V\left(R_{p}\right)^{2} F\left(q, R_{p}\right)^{2} d R_{p}
$$


Finally, when the porosity is filled with waxes, the difference in electron density between particles and waxes should be taken as contrast factor instead of the electron density of the particle itself. Therefore the previous expression becomes :

$\left\langle I\left(q, E_{1}\right)\right\rangle-\left\langle I\left(q, E_{2}\right)\right\rangle \approx$

$\frac{N_{p}}{V_{s}} r_{e}^{2}\left(\left|n_{p} f_{p}\left(E_{1}\right)-n_{m} f_{m}\left(E_{1}\right)\right|^{2}-\left|n_{p} f_{p}\left(E_{2}\right)-n_{m} f_{m}\left(E_{2}\right)\right|^{2}\right) \int_{0}^{+\infty} P_{p}\left(R_{p}\right) V\left(R_{p}\right)^{2} F\left(q, R_{p}\right)^{2} d R_{p}$

\subsubsection{ASAXS measurements}

For ASAXS analysis, the reduced sample was directly embedded in waxes without air exposition in order to prevent reoxidation. The oxide sample was also put into waxes in order to keep the same mode of sample preparation. Then, pellets with a thickness of approximatively $300 \mu \mathrm{m}$ were prepared. Anomalous small-angle X-ray scattering experiments have been performed on the SWING beamline at synchrotron SOLEIL. It involves characterizing cobalt nanoparticles supported on a porous silica-alumina by recording SAXS images around its absorption edge. The advantage of performing ASAXS analyzes is that it suppresses the contribution of the porous support. For this purpose, it is necessary to be close to the cobalt absorption threshold in order to vary the diffusion factor of $\mathrm{Co}$ and thus of the particles, but also to keep constant the diffusion factor of the support. Hence, the scattered intensity was measured at three different energies (see Table 1) 7440, 7647 and $7694 \mathrm{eV}$, slightly below the cobalt K-edge of absorption. The incident beam energy has been calibrated with a metallic cobalt foil. To cover the largest q range, two sample-detector distances $(1000 \mathrm{~mm}$ and $6000 \mathrm{~mm}$ ) have been selected. Furthermore, to increase the sensibility of the photons counting on the peripheral part of the detector, two kinds of beamstop (a small beamstop with a size of $2 \times 1 \mathrm{~mm}^{2}$ and larger beamstop with a size of $3 \times 3 \mathrm{~cm}^{2}$ ) were used. Using the large beamstop, allowed to recorded 2D images with longer exposure time, by masking the strong diffusion around the small beamstop, in order to get better statistics for high q values.In total, four different configurations (detector-sample distance, beamstops) have been used.

The scattering images were recorded using a AVIEX PCCD170170 detector. To increase the statistic of the scattering intensity, thirty images were acquired for each energy and at each detector-sample configuration. The acquisition time was function of the configuration and was chosen in order not to saturate the detector.

Through 1D reduction, raw data were corrected with respect to: acquisition time, geometrical effects like the projection of the detector plane on the sphere with radius equal to the sample-detector distance, detector sensitivity ( $3 \mathrm{ADU} / \mathrm{ph}$, Noise $\approx 2 \mathrm{ADU}$ ), the incoming-photon flux and finally averaged to increase the statistic. The scattering background coming from all components in the beamline and from the air was 
271 measured before each series of acquisition, for each energy and at each configuration. The sample 272 transmission was calculating thanks to the measurement of the incoming and transmitted intensities. It 273 allowed correction of the intensity from the real thickness $(e)$ of the sample, calculated thanks to the 274 composition of the sample obtained by X-Ray Fluorescence and with the following equation:

$$
e=-\frac{\ln T}{\mu_{\text {sample }}}
$$

276

277

$278 \mathrm{~T}$ being the transmission and $\mu_{\text {sample }}$ the linear absorption coefficient $\left(\mathrm{cm}^{-1}\right)$.

280 In order to calibrate the intensity in absolute unities, i.e expressed as differential scattering cross section 281 per unit volume in $\mathrm{cm}^{-1}$, a calibrated NIST glassy carbon [43], was measured at each energy and each 282 configuration. A correction factor has been calculated from the ratio between the NIST data and the 283 experimental data.

\section{$284 \quad$ 2.5.3 Modelling of ASAXS data}

285 The ASAXS results for both oxide and reduced catalysts are given in Figure 1. The plotted curves were 286 obtained from the subtraction of the intensity measured at $E_{2}=7647 \mathrm{eV}$ and the intensity measured at $E_{3}$ $287=7694 \mathrm{eV}$ near the cobalt K-edge of absorption. Noticeable differences can be observed in the q-range 288 between $2.310^{-2} \AA^{-1}$ and $1.210^{-3} \AA^{-1}$. 


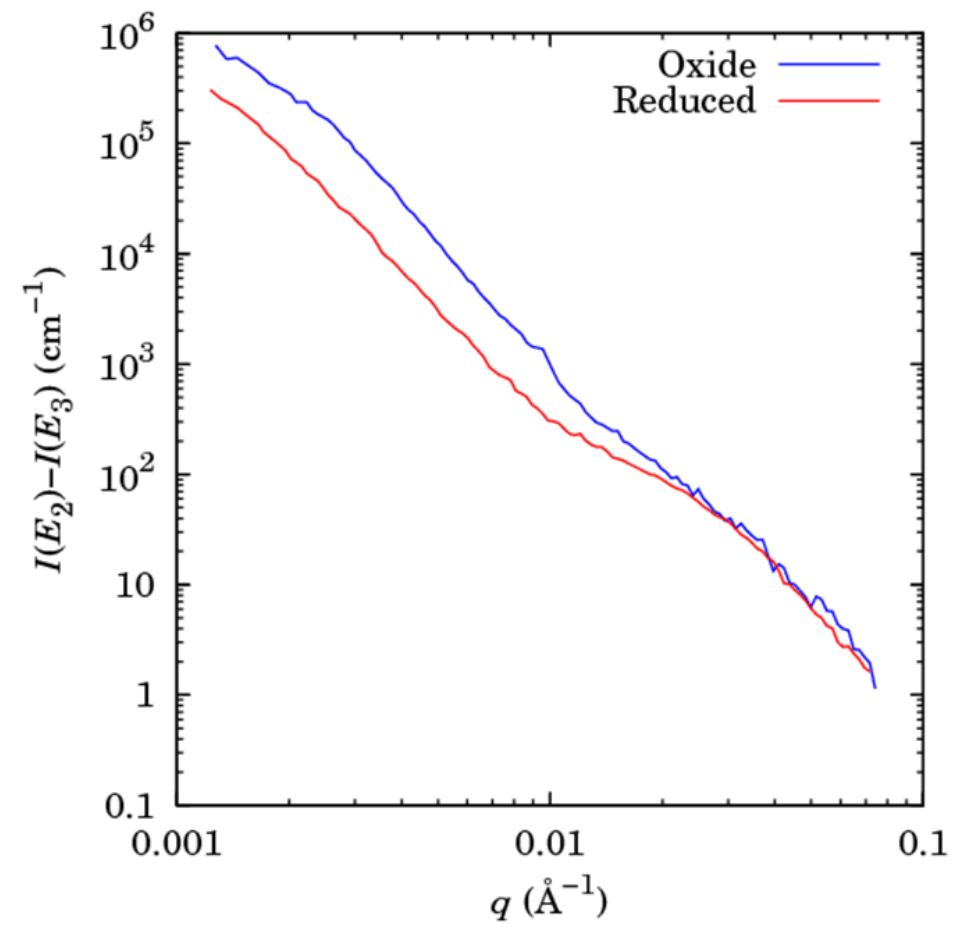

Figure 1. ASAXS curves obtained on oxide and reduced samples

293 In order to evaluate the size distribution of the cobalt particles, a nonlinear least squares adjustment of the 294 ASAXS signal is performed. The assumptions made for the choice of the regression model are listed 295 below

296 Given the shape of the curves (two inflections of the scattered signal), the experimental data could not be 297 fitted with only one function of size distribution. It appears that two kinds of cobalt particles exist in the 298 catalyst, at the oxide and at the reduced state, at two different scales. Based on the electron microscopy 299 observations, these two populations are attributed to isolated, dense and crystalline particles at the small 300 scale, and to larger, polycrystalline and moderately dense aggregates at large scale. This assumption will 301 be corrobated in this paper.

303 For the cobalt phase, we thus consider that the scattering objects can be porous. The porosity is so called $\varepsilon$ 304 and is filled with waxes. In the case of the crystalline particles, $\varepsilon=0$ and in the case of cobalt aggregate, $\varepsilon$ $305>0$

306 The number of cobalt atoms in the scattering object and the number of the matrix atoms are respectively 307 defined by:

$$
N_{\text {Cox }}=\frac{N_{A} \times \rho_{\operatorname{Cox}}}{M_{\text {Cox }}} \times V \times(1-\varepsilon)
$$




$$
N_{m}=\frac{N_{A} \times \rho_{m}}{M_{m}} \times V \times \varepsilon
$$

311 With $\mathrm{Co}_{\mathrm{x}}=\mathrm{Co}_{3} \mathrm{O}_{4}$ in the case of oxide cobalt and $\mathrm{Co}_{\mathrm{x}}=\mathrm{Co}^{0}$ in the case of metallic cobalt, $\mathrm{V}$ the volume 312 of the scattering object, $N_{A}$ the Avogadro number $\left(6.022 \times 10^{23} \mathrm{~mol}^{-1}\right), M_{C o x}$ and $M_{m}$ the molar masses in $313 \mathrm{~g} / \mathrm{mol}, \rho_{C o x}$ and $\rho_{m}$ the densities of both phases in $\mathrm{g} / \mathrm{cm}^{3}$.

314 Hence, the scattering factor of a cobalt particle is defined by :

$$
n_{p} f_{p}=\left(\frac{N_{A} \times \rho_{\operatorname{Cox}}}{M_{\text {Cox }}} \times f_{\text {Cox }}\right) \times(1-\varepsilon)+\left(\frac{N_{A} \times \rho_{m}}{M_{m}} \times f_{m}\right) \times \varepsilon
$$

It follows:

$$
n_{p} f_{p}-n_{m} f_{m}=\left(\frac{N_{A} \times \rho_{\operatorname{Cox}}}{M_{\text {Cox }}} \times f_{\text {Cox }}-\frac{N_{A} \times \rho_{m}}{M_{m}} \times f_{m}\right) \times(1-\varepsilon)=\left(n_{\operatorname{Cox}} f_{\text {Cox }}-n_{m} f_{m}\right) \times(1-\varepsilon)
$$

319 The term $\frac{N_{p}}{V_{s}}$ of the equation (9) can be expressed as:

$$
\frac{N_{p}}{V_{S}}=\frac{w_{\operatorname{Cox}} \times \rho_{s}}{\rho_{\operatorname{Cox}}} \times \frac{1}{1-\varepsilon} \times \frac{1}{\langle V\rangle}
$$

With $\langle V\rangle$ the mean volume of the particle aggregate $\left(\mathrm{cm}^{-3}\right), \mathrm{w}_{\mathrm{Cox}}$ the weight content of the cobalt phase (wt.\%), $\rho_{s}$ the sample density in $\mathrm{g} / \mathrm{cm}^{3}$.

The particles are considered to be spherical and isolated: as so, the structure factor is not taken into account while the form factor is. Thus the form factor for a spherical particle is:

and

$$
\begin{gathered}
F^{2}\left(q, R_{p}\right)=\left[3 \frac{\sin \left(q, R_{p}\right)-q R_{p} \cos \left(q, R_{p}\right)}{\left(q, R_{p}\right)^{3}}\right]^{2} \\
V\left(R_{p}\right)=\frac{4}{3} \pi R_{p}{ }^{3}
\end{gathered}
$$

The size distributions can be represented by a sum of log-normal distribution:

$$
P_{i}\left(R_{p}\right)=\frac{1}{\sqrt{2 \pi} R_{p} \sigma_{i}} \exp \left(-\frac{\left(\ln R_{p}-\mu_{i}\right)^{2}}{2 \sigma_{i}^{2}}\right)
$$

332 In order to calculate the number and volume average sizes from the adjusted log-normal distribution, the distribution moments $M_{n}$ must be known [44]:

$$
M_{n}=\exp \left(\mu n+\frac{n^{2} \sigma^{2}}{2}\right)
$$

The volume size distribution $\mathrm{P}_{\mathrm{v}}$ is defined by: 


$$
P_{i v}\left(R_{p}\right)=\frac{R_{p}^{3} P\left(R_{p}\right)}{M_{3}}
$$

The number, the surface and the volume mean sizes can be calculated:

$$
R=\frac{M_{1}}{M_{0}}=\exp \left(\mu+\frac{\sigma^{2}}{2}\right), R_{\text {surf }}=\frac{M_{3}}{M_{2}}=\exp \left(\mu+\frac{5 \sigma^{2}}{2}\right) \text { and } R_{\text {vol }}=\frac{M_{4}}{M_{3}}=\exp \left(\mu+\frac{7 \sigma^{2}}{2}\right)
$$

Given the shape of the curves (two inflections of the scattered signal), we chose to model the distribution of cobalt by two log-normal distributions:

$$
\begin{aligned}
\left\langle I\left(q, E_{1}\right)\right\rangle-\left\langle I\left(q, E_{2}\right)\right\rangle & \\
& \approx r_{e}^{2}\left(\left|n_{p} f_{p}\left(E_{1}\right)-n_{m} f_{m}\left(E_{1}\right)\right|^{2}-\left|n_{p} f_{p}\left(E_{2}\right)-n_{m} f_{m}\left(E_{2}\right)\right|^{2}\right) \\
& \times\left[\frac{N_{p 1}}{V_{s}} \int_{0}^{+\infty} P_{1}\left(R_{p}\right) V\left(R_{p}\right)^{2} F\left(q, R_{p}\right)^{2} d R_{p}+\frac{N_{p 2}}{V_{s}} \int_{0}^{+\infty} P_{2}\left(R_{p}\right) V\left(R_{p}\right)^{2} F\left(q, R_{p}\right)^{2} d R_{p}\right]
\end{aligned}
$$

With

$$
\frac{N_{p 1}}{V_{s}}=\frac{w_{C o x} \times \rho_{s}}{\rho_{C o x}} \times w_{1} \times \frac{1}{1-\varepsilon_{1}} \times \frac{1}{\left\langle V_{1}\right\rangle} \text { and } \frac{N_{p 2}}{V_{s}}=\frac{w_{C o x} \times \rho_{s}}{\rho_{C o x}} \times w_{2} \times \frac{1}{1-\varepsilon_{2}} \times \frac{1}{\left\langle V_{2}\right\rangle}
$$

$\langle V\rangle$ is the mean volume such as :

$$
\langle V\rangle=\frac{4}{3} \times \pi \times \int R_{p}{ }^{3} P(R) d R=\frac{4}{3} \times \pi \times M_{3}=\frac{4}{3} \times \pi \times \exp \left(3 \mu+\frac{9 \sigma^{2}}{2}\right)
$$

Supposing that the first particle population corresponds to dense, crystalline and isolated particles and that the second one is attributed to aggregates partially dense, the previous equation becomes:

$\times\left[\frac{1}{<V_{1}>} \int_{0}^{\infty} P_{1}\left(R_{p}\right) V^{2}\left(R_{p}\right) F^{2}\left(q, R_{p}\right) d R_{p}+\frac{w_{2}\left(1-\varepsilon_{2}\right)}{w_{1}} \times \frac{1}{<V_{2}>} \int_{0}^{\infty} P_{2}\left(R_{p}\right) V^{2}\left(R_{p}\right) F^{2}\left(q, R_{p}\right) d R_{p}\right]$

With $\mathrm{w}_{1}$ and $\mathrm{w}_{2}$ the cobalt weight percent of the first and second population of particles, and

This model allows estimating the size distribution of the particles $\left(\mu_{1}, \sigma_{1}\right)$, the size distribution of the aggregates $\left(\mu_{2}, \sigma_{2}\right)$ and the parameter $\frac{w_{2}\left(1-\varepsilon_{2}\right)}{w_{1}}$ which depends on the ratio between the cobalt content

$$
\Delta \rho_{\text {Cox }}^{2}\left(E_{i}, E_{j}\right)=\left(n_{\text {Cox }} f_{\text {Cox }}\left(E_{i}\right)-n_{m} f_{m}\right)^{2} \times r_{e}^{2}-\left(n_{\text {Cox }} f_{\text {Cox }}\left(E_{j}\right)-n_{m} f_{m}\right)^{2} \times r_{e}{ }^{2}
$$
included in the first and in the second population, but also on the porosity of the aggregates. 
360 An example of fit is shown on Figure 2 for the oxide sample. The first part of the curve (from $10^{-1} \AA^{-1}$ to $\left.3611.410^{-2} \AA^{-1}\right)$ is essentially due to the contribution of the first population of small-size particles whereas 362 the second part of the curve (from $1.410^{-2} \AA^{-1}$ to $1.210^{-3} \AA^{-1}$ ) is due to the contribution of the second 363 population of larger objects called aggregates.

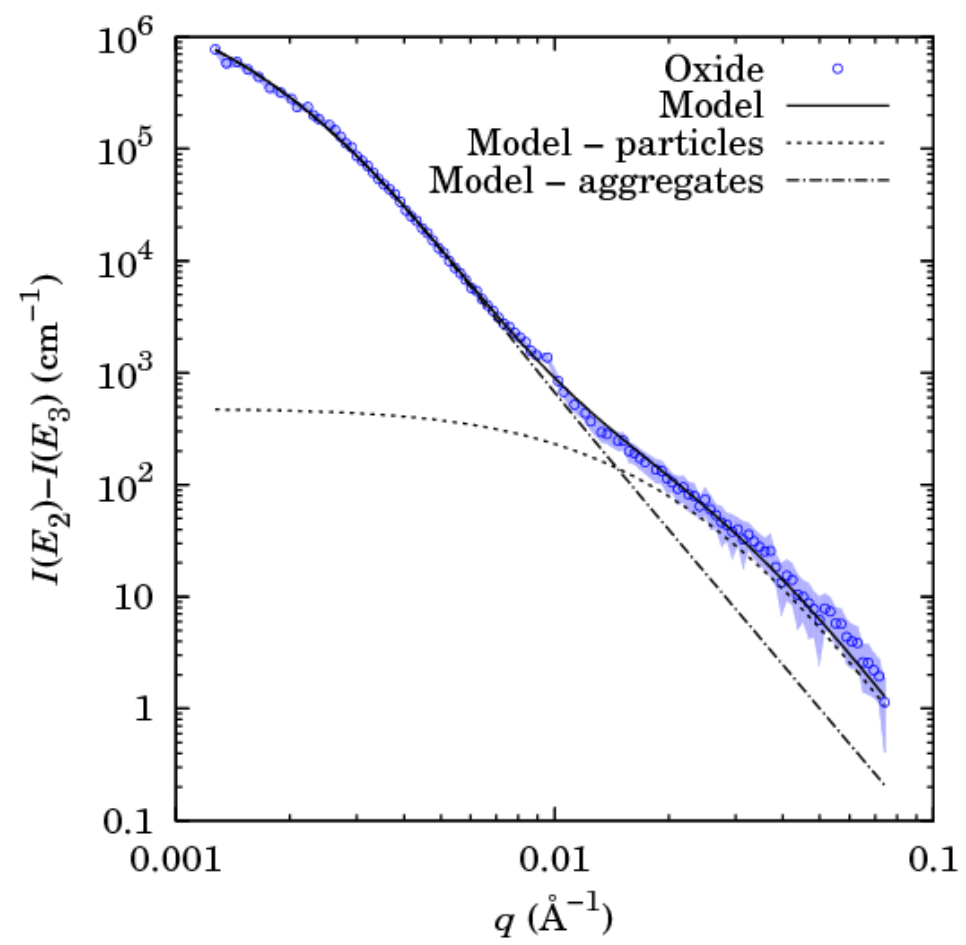

Figure 2. Fit of the experimental ASAXS data of the oxide sample.

\section{$368 \quad 3$ Results}

\section{$369 \quad 3.1 \quad$ Particle scale}

370 Cobalt particle size distribution was measured by dark-field transmission electron microscopy and also 371 obtained by ASAXS.

372 Figure 3 a presents a representative image of dark-field TEM of cobalt nanoparticles supported on silica373 alumina. Figure $3 \mathrm{~b}$ presents the size distribution in both oxide (blue) and reduced (green) catalysts. Both 374 size distributions present the same general shape, and few differences are observed.

375 Besides, the volume size distribution $\left(\mathrm{P}_{\mathrm{v}}\right)$ of the particles obtained by ASAXS for both catalysts thanks to 376 the fit of the experimental data are plotted on Figure 4. The two size distributions are slightly different as 
revealed by the $\mu$ and $\sigma$ parameters of the lognormal-law (3.29 and 0.56 for the oxide sample versus 3.56 and 0.44 for the reduced sample) however the differences are faint.

380 In order to compare TEM, ASAXS measurements and XRD mean size, all results are expressed by the 381 volume mean particle radius. ASAXS, TEM and XRD data on oxide samples are totally consistent, 382 considering uncertainties of both techniques. It is noteworthy that a very good agreement is obtained 383 between ASAXS and TEM results for the oxide sample contrary to the case of the reduced sample. This 384 can be accounted for by the $47 \%$ reduction rate, measured by XANES. Indeed, less than half of the cobalt is reduced and thus in the metallic $\mathrm{Co}^{\circ}$ phase. Moreover, it is known that the small particles are less reducible than the big ones. Due to its principle, the dark-field TEM allows observing and counting solely $\mathrm{Co}^{\circ}$ particles, whereas the ASAXS technique characterizes all the cobalt either oxide or metallic. This could explain the mean size differences obtained with both techniques, and also the higher mean size particle measured on the reduced sample by TEM compared to the oxide catalyst.

These ASAXS analyses tend to show a decrease in size during reduction, which agrees with the fact that the reduced $\mathrm{Co}^{0}$ particles are smaller than the oxide $\mathrm{Co}_{3} \mathrm{O}_{4}$ particles due to the crystallographic structure contraction of around 0.8 . However it is difficult to conclude on the effect of the reduction of the particle size as it seems to be very tight and hidden by the large distribution of the particle size and the significant heterogeneity of the samples.
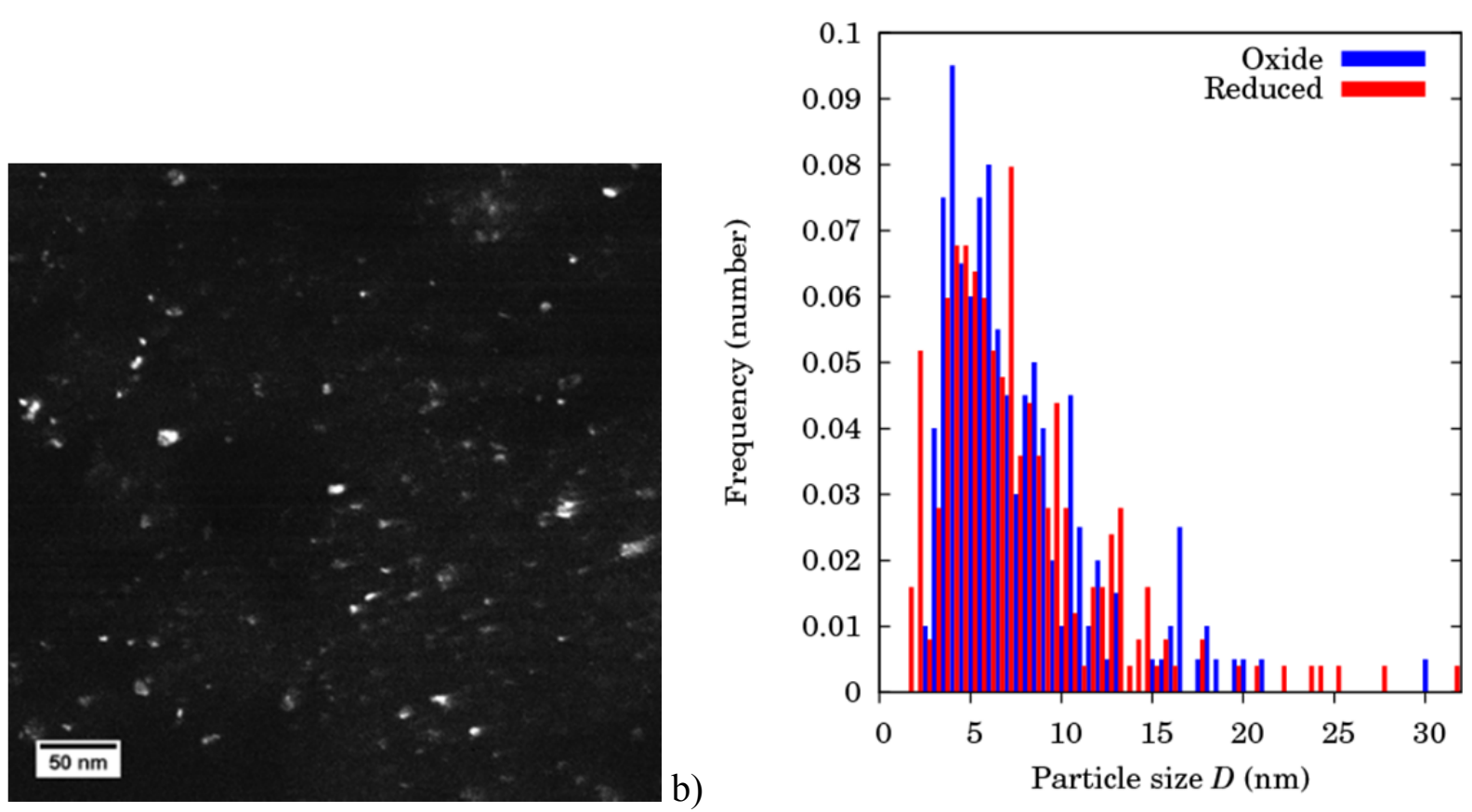
expressed by number frequency: in oxide catalyst (blue) and reduced catalyst (red) 
Table 2: Cobalt particle sizes measured by different techniques

\begin{tabular}{|l|c|c|}
\hline & Oxide catalyst & Reduced catalyst \\
\hline DF TEM - volume mean size (nm) & $16.1 \pm 2.4$ & $18.0 \pm 2.7$ \\
\hline ASAXS - volume mean size (nm) & 16.2 & 14.5 \\
\hline XRD - volume mean size (nm) & $16.6 \pm 2.0$ & $/$ \\
\hline
\end{tabular}

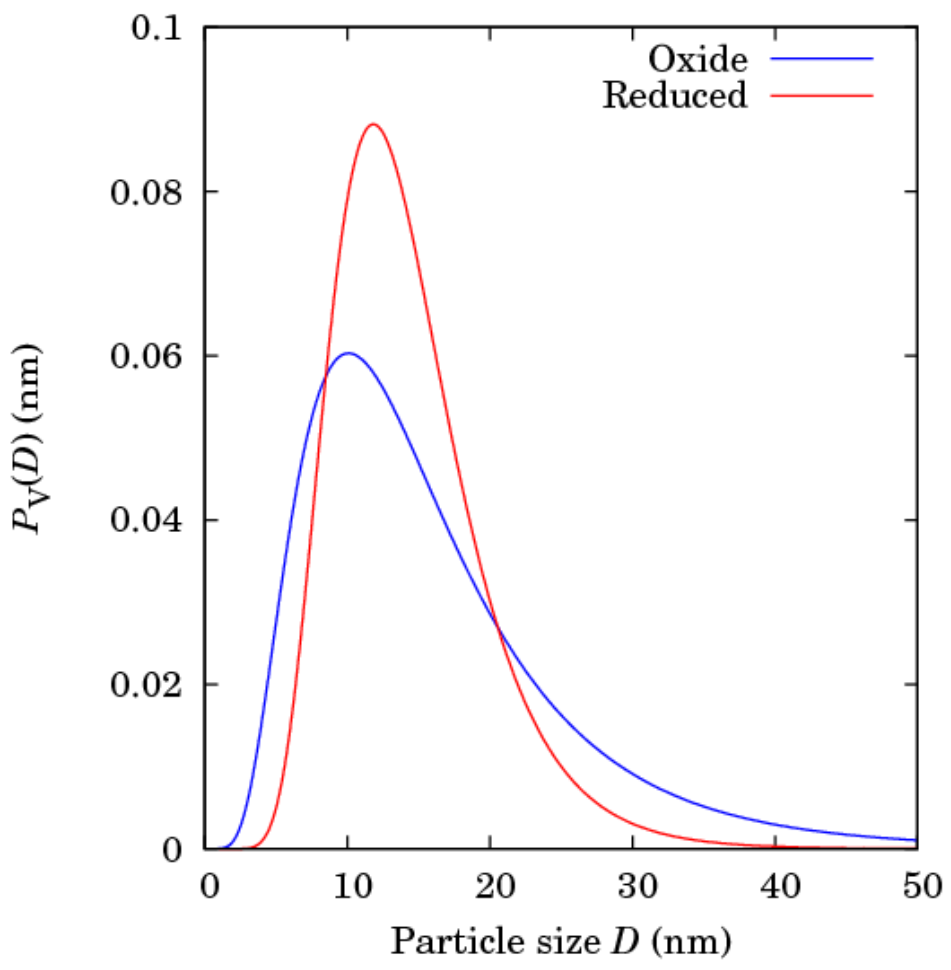

Figure 4 : Volume size distribution (Pv) obtained for the oxide and the reduced catalysts by ASAXS.

\subsection{Cobalt aggregates characterization by HAADF-STEM and electron tomography}

Cobalt aggregates in the catalysts grains were observed at different scales. First of all, SEM observations on several grains of the oxide catalyst were performed and have showed a strong heterogeneity in the Co aggregates repartition inside a grain and from on grain to another. Furthermore, the scale of 413 characterization was too large to precisely their size. Thus, HAADF-STEM observations were carried out 414 on ultramicrotomy cuts. Representative images for the oxide and reduced catalysts are presented on 
415 Figure 5. They have revealed that aggregates repartition and even size can strongly vary from a grain to 416 another. Nevertheless, measurements were performed on more than 200 aggregates in each catalyst and 417 their size distribution is presented on Figure 6 . The mean size in oxide catalyst corresponds to $52 \mathrm{~nm}$ and 418 to $54 \mathrm{~nm}$ in reduced one.

419 ASAXS analysis has also allowed to obtain the number size distribution $\left(\mathrm{P}_{\mathrm{N}}\right)$ of the aggregates for both 420 catalysts thanks to the fit of the experimental data (see Figure 7). The maximum of the distribution in the 421 reduced sample is slightly shifted to smaller size than in the oxide one. The mean number size of the oxide catalyst is $85 \mathrm{~nm}$ versus $49 \mathrm{~nm}$ for the reduced one. However the standard deviation is quite high, meaning that the aggregates size can vary from 20 to almost $200 \mathrm{~nm}$. : the lognormal-law parameters $(\mu$ and $\sigma$ that are, respectively) were found to be 5.91 and 0.55 for the oxide catalyst and 5.16 and 0.83 for the reduced one.

ASAXS and STEM measurements are in good agreement concerning the aggregates mean size of the reduced sample (54 and $49 \mathrm{~nm}$ ) but a small difference exists for the oxide sample, even if the ASAXS and STEM values (52 and $85 \mathrm{~nm}$ ) are in the same order of magnitude. However, we have discussed that the sample heterogeneity and the cobalt distribution from one grain to another was significant, which could explain the differences. Considering heterogeneity of the samples and standard deviations of the distribution, it can be concluded that the aggregate diameter does not evolve significantly during reduction. Hence, reduction under $\mathrm{H}_{2}$ at $400^{\circ} \mathrm{C}$ does not lead to aggregate sintering neither to large scale redistribution of cobalt in the support. Cobalt aggregates microstructure was studied by dark-field transmission electron microscopy. Both electron diffraction patterns and DF-TEM images reveal an important change of morphology during reduction. Indeed, oxide cobalt aggregates present a dense structure with indistinct particles, i.e consisting of coherent domains having rather the same crystalline orientation but with some structural stacking faults (Figure 9). On the other hand, metallic cobalt aggregates present a clearly polycrystalline structure (Figure 10), and crystals forming the aggregates even seem to be disjoint. It is confirmed by high magnification HAADF-STEM images (Figure 8). In oxide catalyst, aggregates look compact, with a uniform contrast, whereas in reduced catalyst, individual 

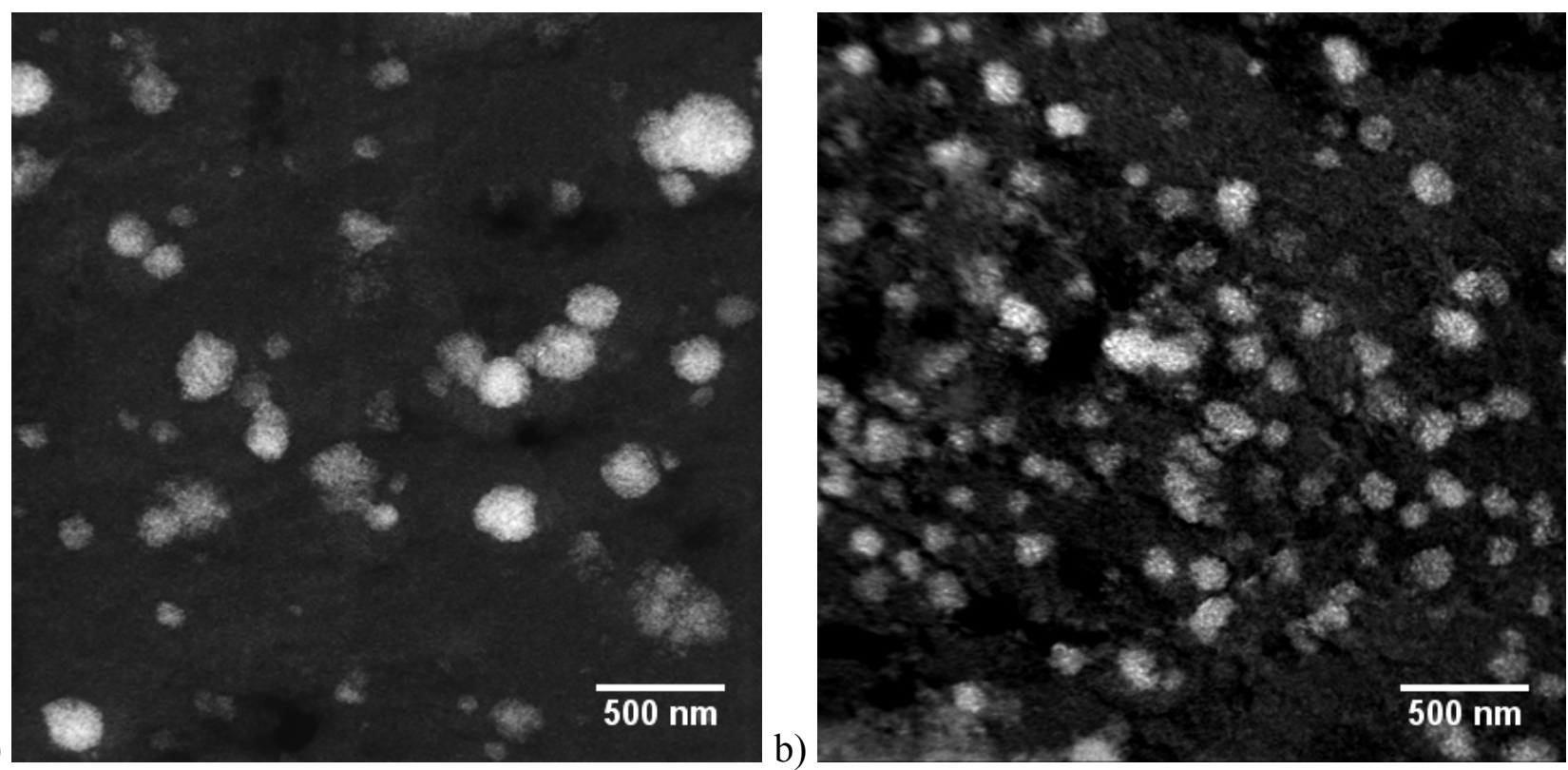

Figure 5 : HAADF-STEM images of a) oxide catalyst ; b) reduced catalyst.

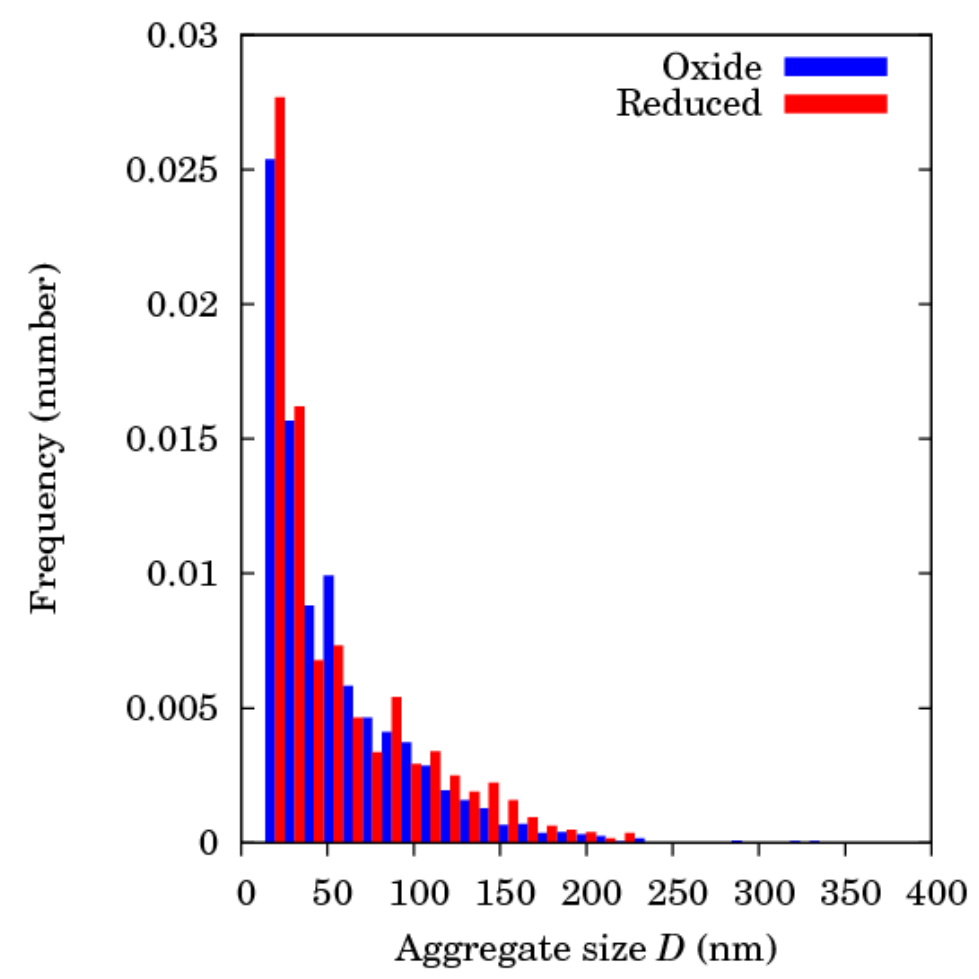

Figure 6 : Cobalt aggregates size distribution, measured by HAADF-STEM, expressed by number frequency: in oxide catalyst (blue) and reduced catalyst (red) 


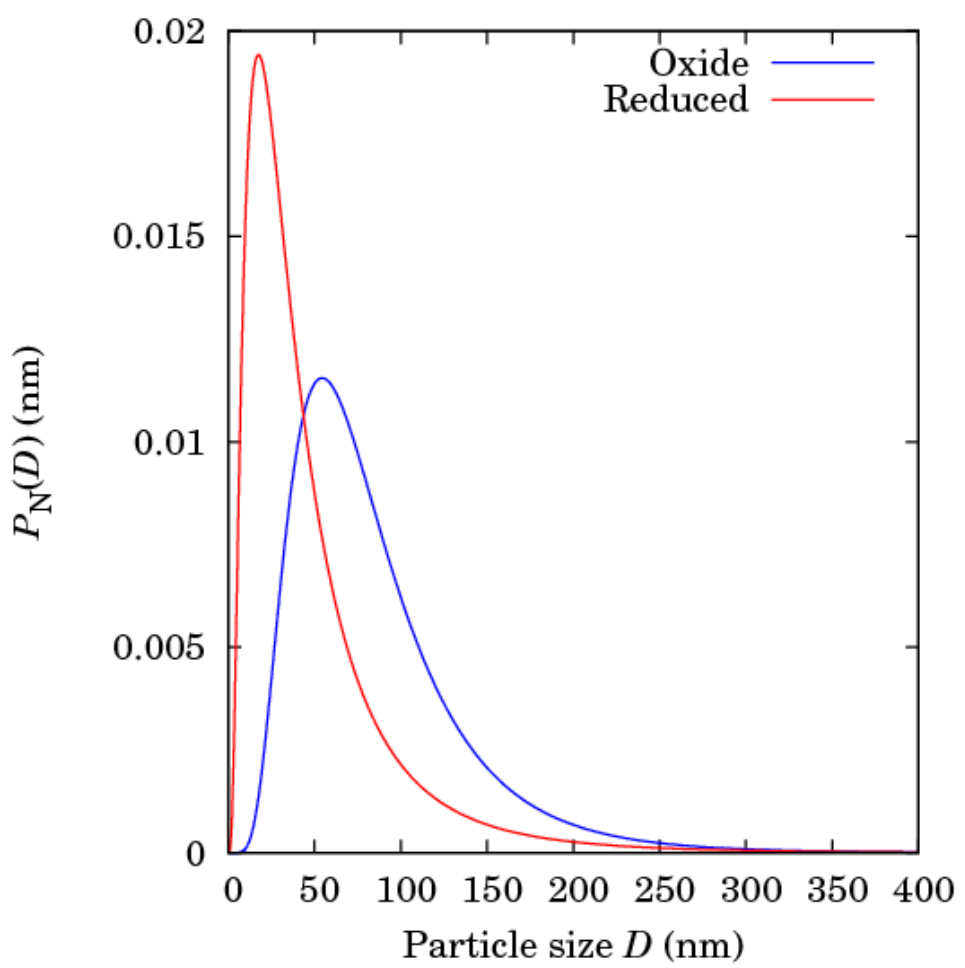

Figure 7 : Number aggregates size distribution $\left(P_{N}\right)$ obtained by ASAXS for the oxide and the reduced catalysts.
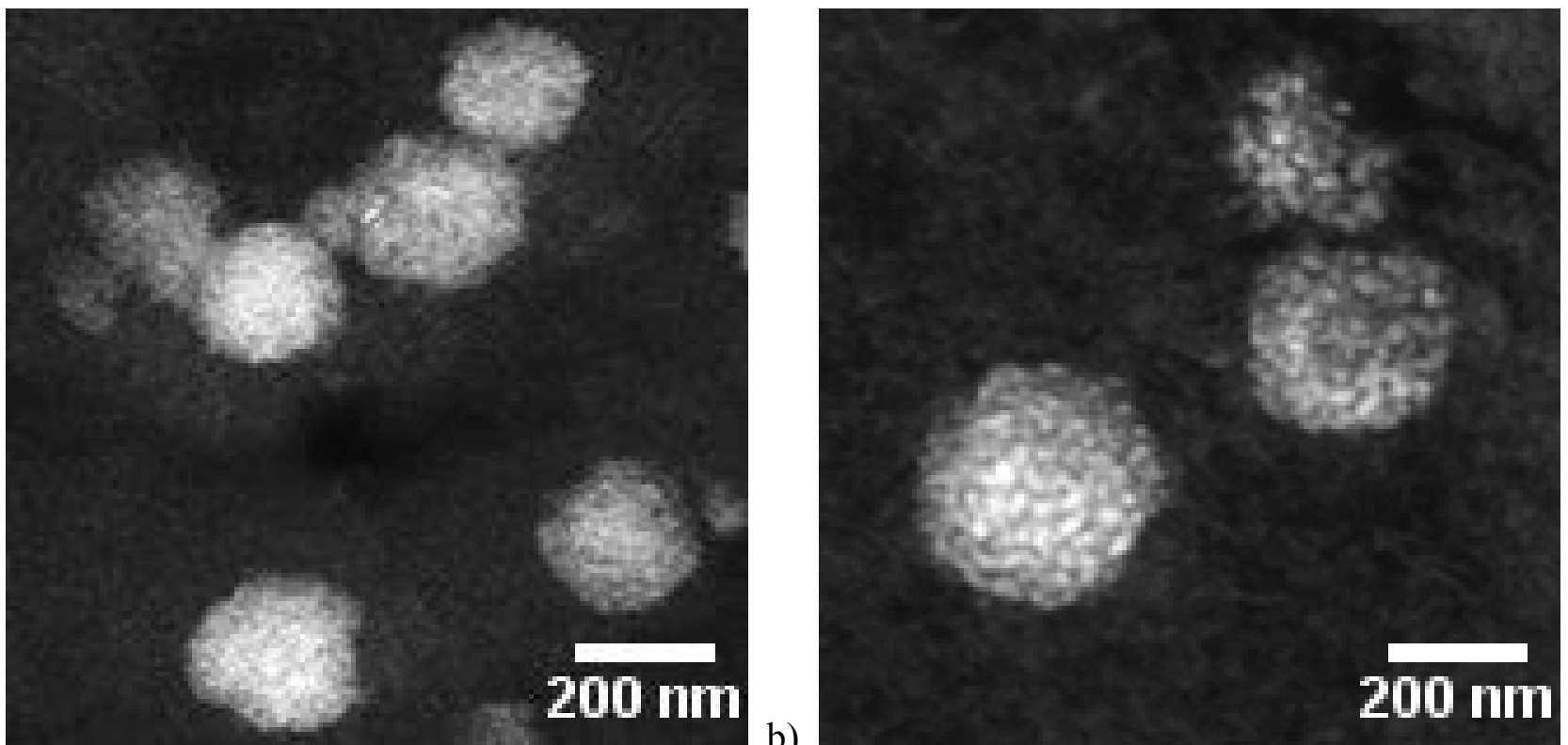

Figure 8 : High magnification HAADF-STEM images of a) oxide catalyst ; b) reduced catalyst. 
a)

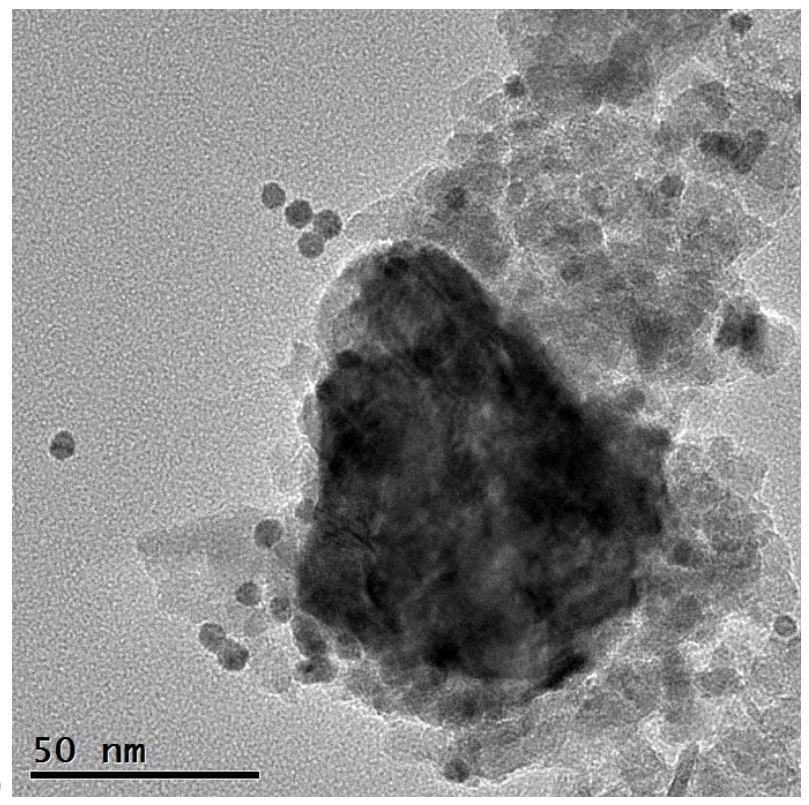

b)

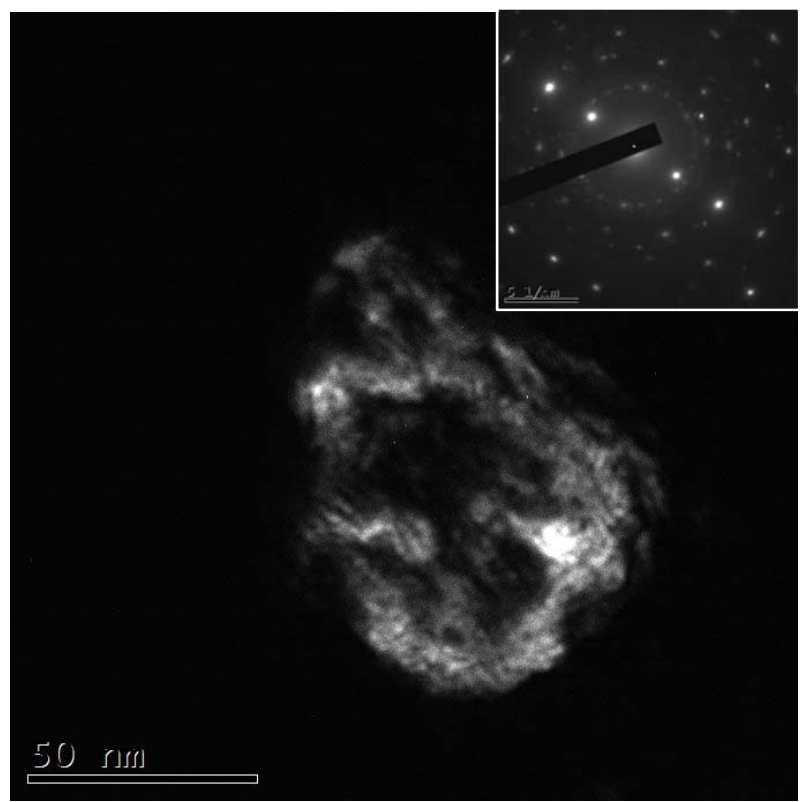

Figure 9 : a) Bright-field TEM ; b) Dark field TEM images and in insert electron diffraction pattern of a cobalt aggregate in the oxide catalyst.
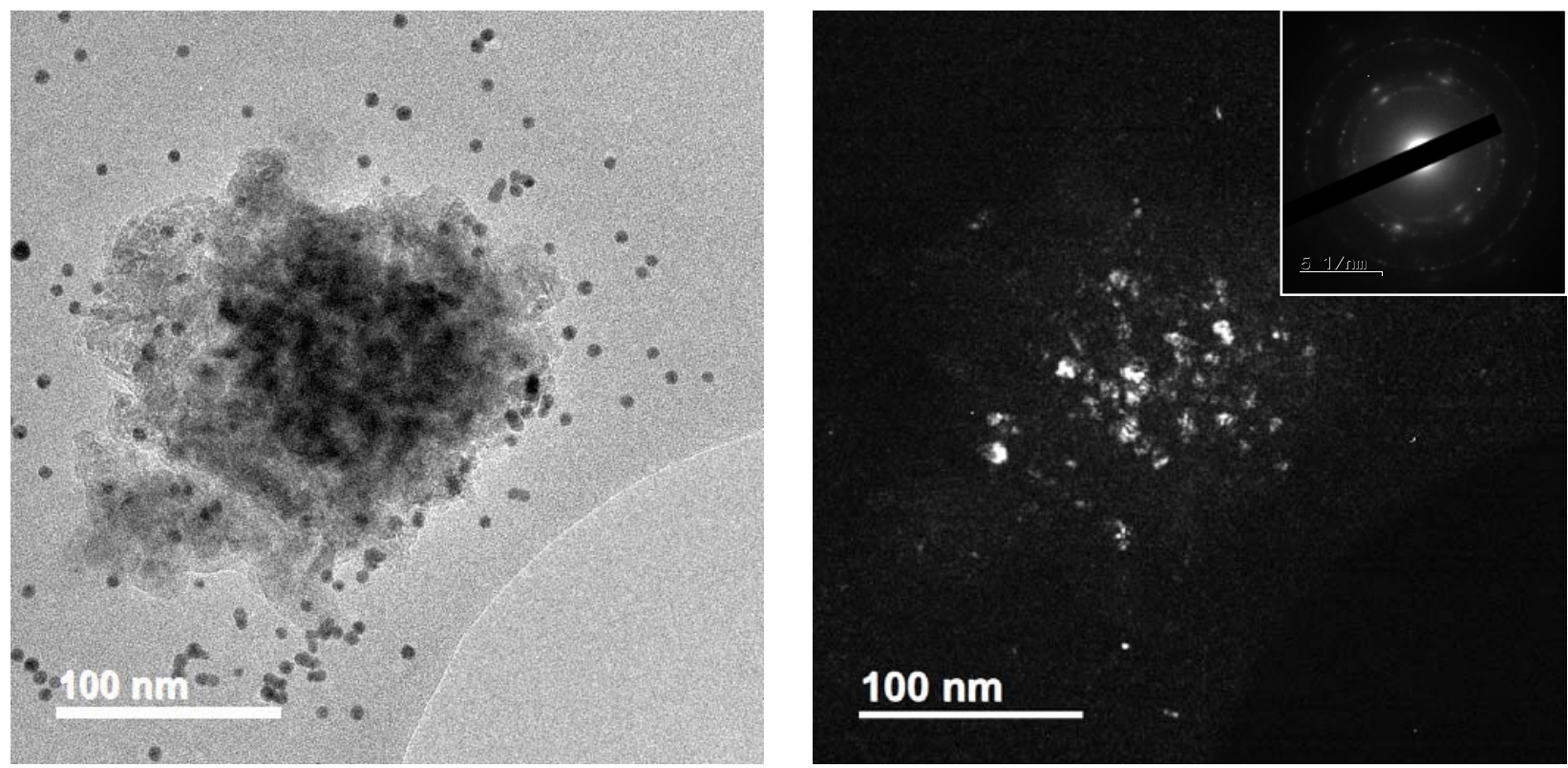

Figure 10 : a) Bright-field TEM ; b) Dark field TEM images and in insert electron diffraction pattern of a cobalt aggregate in the reduced catalyst. 
aggregates $(>100 \mathrm{~nm})$ are too thick for electron tomography acquisitions. $50 \mathrm{~nm}$-diameter aggregates were selected, corresponding to the mean size obtained from HAADF-STEM images.

Figure 11 depicts cross sections of the reconstructed volume of a cobalt aggregate in the oxide catalyst. The aggregate appears in dark in the image (the contrast was inverted after the acquisition and before reconstruction) and the support is visible in light grey. The aggregate is a compact and dense phase of cobalt, with some spherical or cylindrical closed pores in its centre.

a)

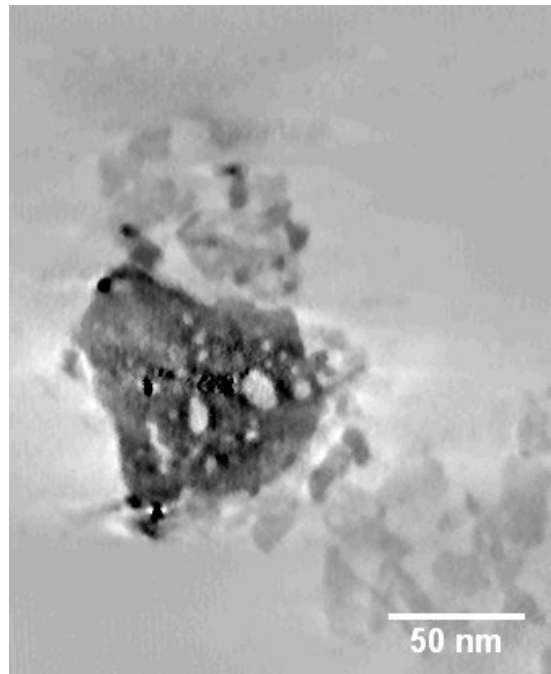

b)

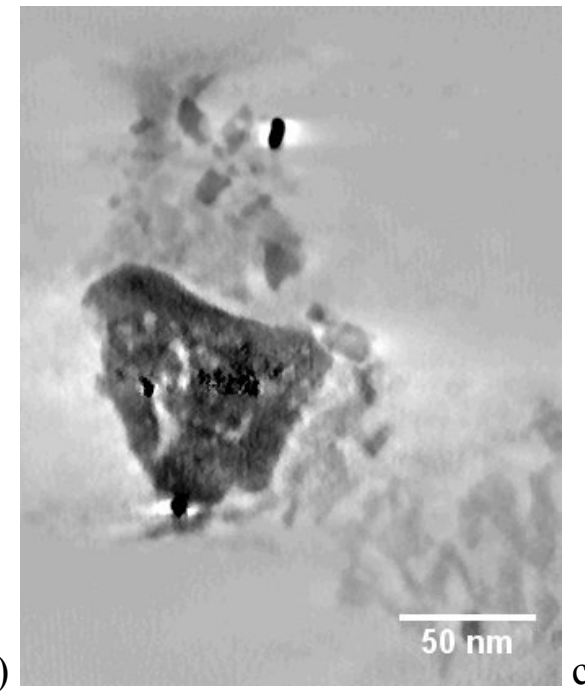

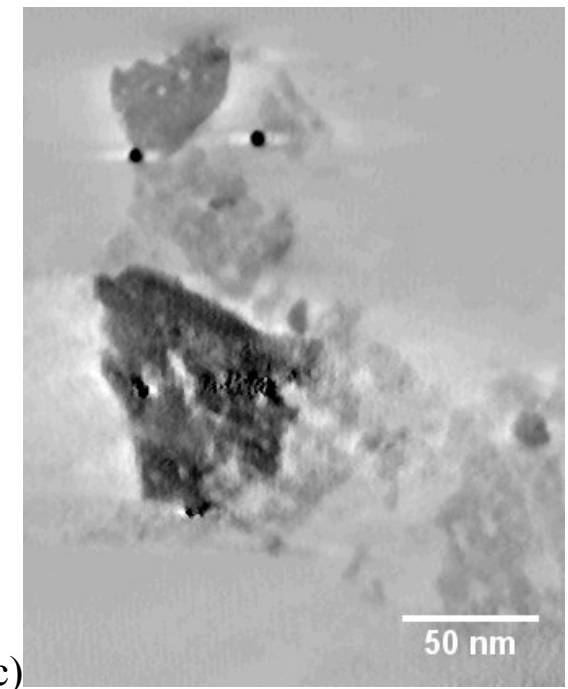

Figure 11 : a-c) Slices from electron tomography reconstructions for a cobalt aggregate in the oxide catalyst.
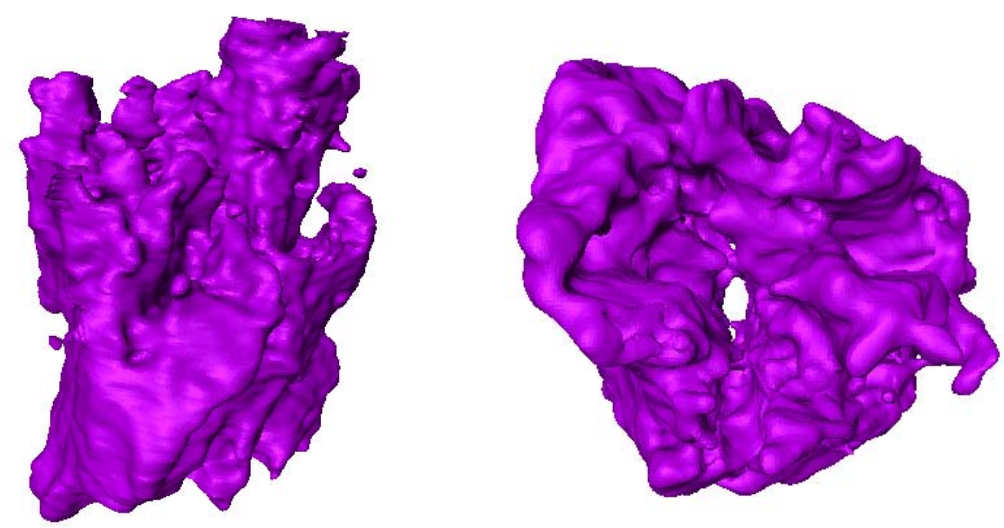

\section{Figure 12: Model of a cobalt aggregate in the oxide catalyst, obtained by segmentation of the electron tomography reconstruction. Two different orientations.}

Segmentation of the reconstructed volume allowed to model the aggregate. A 3D representation of the model aggregate is presented on Figure 12. Only the cobalt phase was segmented independently to the 
487 silica-alumina support. Indeed, the contrast of the support compared to porosity is too weak to be 488 segmented without important error. It confirms the compact structure of the aggregate. In particular, the 489 external surface of the aggregate is very smooth. Accessibility of cobalt is a key factor for catalysis. We 490 defined two parameters to estimate the accessibility of cobalt in aggregates. The first one, called 491 "aggregate dispersion", is calculated as the ratio between surface cobalt to total cobalt and the second one 492 is the porosity inside the aggregate. From the aggregate model obtained by electron tomography, the 493 "aggregate dispersion" is estimated to $18 \%$ and the porosity to $35 \%$. "Aggregate dispersion" takes into 494 account the surface roughness of the aggregate and is different from dispersion classically obtained by 495 chemisorption.

496 Figure 13 depicts a cross section of the reconstructed volume of a cobalt aggregate in the reduced 497 catalyst. The aggregate appears in dark in the image. Here, the support is slightly visible compared to 498 porosity. The aggregate is a porous and airy phase of cobalt, composed of almost independent particles 499 with large inter-particle porosity.

500 A 3D representation of the model aggregate, obtained by segmentation of the reconstructed volume is 501 presented on Figure 14. Here again, only the cobalt phase was selected for modeling independently from 502 the support. The sponge-like structure of the cobalt aggregate in the reduced sample is clearly highlighted. 503 Contrary to the compact morphology on the oxide state, the aggregate presents a large external surface, 504 leading to high accessibility. From the aggregate model, the "aggregate dispersion" is estimated to $27 \%$ 505 and the porosity to $65 \%$.

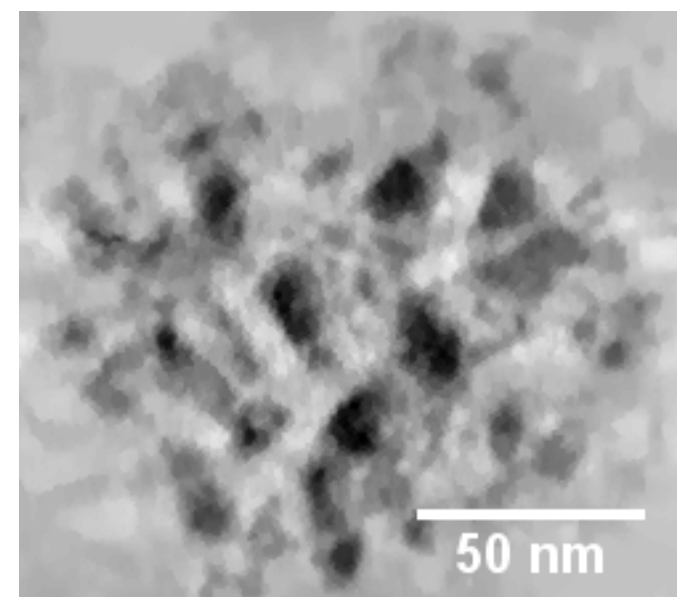



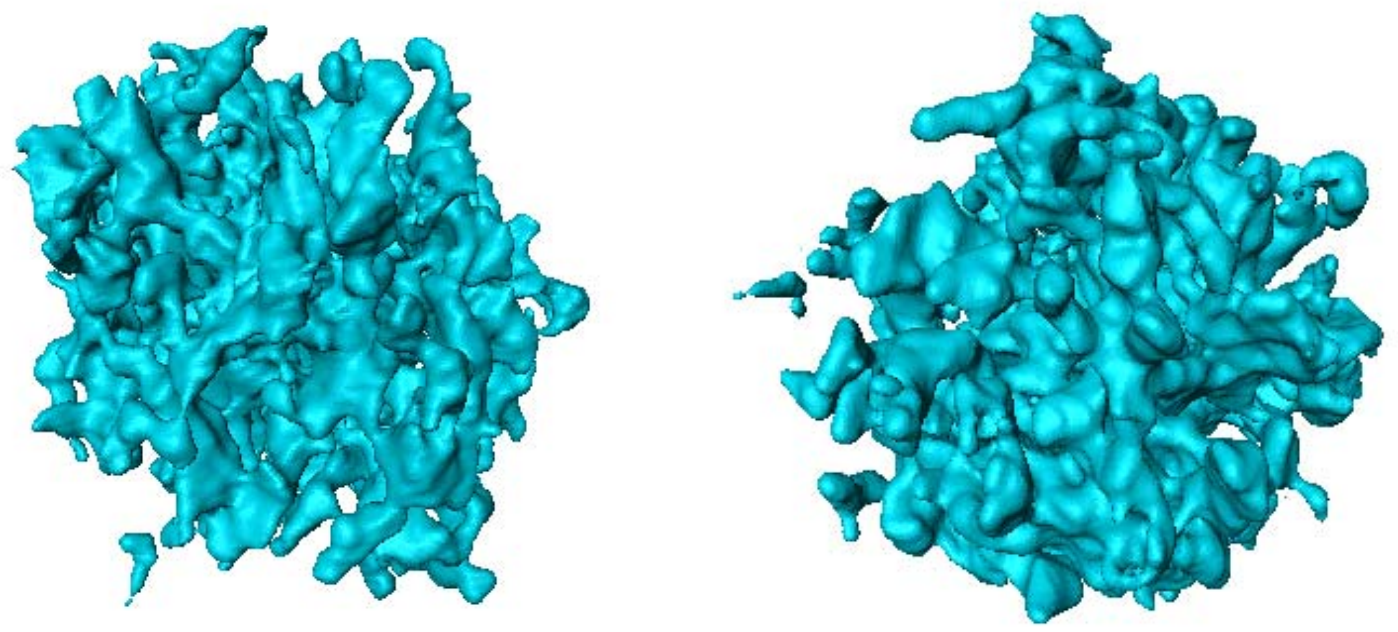

Figure 14: Model of a cobalt aggregate in the reduced catalyst, obtained by segmentation of the electron tomography reconstruction. Two different orientations.

515 Besides these deep electron tomography characterizations, ASAXS also provides information on the 516 aggregate structure. Indeed, the model used to fit the ASAXS data makes it possible to calculate the $517 \frac{w_{2}\left(1-\varepsilon_{2}\right)}{w_{1}}$ parameter. It was found to be 3.05 for the oxide sample and 1.11 for the reduced sample.

518 Supposing that the ratio between the cobalt content included in the first and in the second populations 519 (particles and aggregates) does not evolve during the reduction step, we can suggest that the ratio $520 \frac{\left(1-\varepsilon_{2}\right)_{\text {reduced }}}{\left(1-\varepsilon_{2}\right)_{\text {oxide }}}$ equals to 0.364 , which implies that the compacity of the reduced aggregates $\varepsilon_{2}$ is almost 2.8 521 times less significant than the one of the oxide aggregates. Hence, ASAXS analysis also lead to conclude 522 that during the reduction, the aggregate structure becomes airier and more porous.

523 Furthermore, to check the good agreement between ASAXS and electron tomography, setting the oxide 524 aggregate porosity equal to $35 \%$ as calculated by electron tomography, the ratio $\frac{\left(1-\varepsilon_{2}\right)_{\text {reduced }}}{\left(1-\varepsilon_{2}\right)_{\text {oxide }}}$ of 0.364 525 obtained by ASAXS leads to a calculated aggregate porosity of $76 \%$ for the reduced sample. Even if the 526 porosity is not exactly the same when calculated by electron tomography or by ASAXS, the same trend is 527 observed with the same order of magnitude. Both techniques are in good agreement but each provides 528 different benefits. Electron tomography provides local information and could suffer from 529 representativeness issues, it allows visualizing the object of the study and justify the kind of model 530 employed to fit the ASAXS data (spherical particles and aggregates, log-normal distribution of size).

531 Besides, ASAXS technique is less familiar but as the advantage to be a bulk analysis which provides 532 representative information of the whole sample. Hence, both technique are complementary. 
They underline the strong effect of the reduction step on the aggregate structure: the oxide aggregate are dense with indistinct particles, i.e consisting of coherent domains having rather the same crystalline orientation, but structural stacking faults and with some spherical or cylindrical closed pores, whereas the reduced aggregates are clearly polycrystalline with visible individual particles with large inter-particle porosity, which leads to a porous and airy structure. The oxide aggregate porosity is certainly formed during the calcination step under thermal stresses or due to defects relative to the non-uniform cobalt impregnation. The reduced aggregate porosity is formed during the reduction step and is supposed to be caused by the crystallographic phase transformation inducing an increase of the crystalline density of the cobalt, leading to voids formation between particles. However, this porosity could not be explained by the sole crystallographic phase transformation as it theoretically induces an aggregate density decrease of $20 \%$, which is inferior to the decrease of $36 \%$ measured by ASAXS, or 54\% measured by tomography. Thermal stresses could thus be invoked in order to explain the high magnitude of porosity creation.

This structure change with the porosity increase during the reduction step appears to be very important as it increases the "aggregate dispersion" (from $18 \%$ to $25 \%$ ) and thus increases the number of accessible cobalt active sites. The activity of the FT catalysts depending essentially on this number of accessible metallic cobalt active sites, the optimization of the reduction step conditions in order to optimise the creation of the porosity seems to be an interesting approach to improve the catalyst activity. Furthermore, the FT catalyst selectivity is suspected to be sensitive to the proportion and size of the aggregates [8] that are known to be controlled by the drying and calcination steps, hence to the active sites proximity. Once again the aggregate structure and thus the reduction conditions could impact the selectivity. We can suppose for example that varying the gas hourly space velocity, heating ramp, temperature, or the pressure could lead to different aggregate structures.

\section{Conclusion}

In this study we have proposed a new approach that combines electron microscopy and ASAXS to characterize Fischer-Tropsch cobalt-based catalysts in order to obtain a detailed and exhaustive description of cobalt active phase. This last one is composed of dispersed nanoparticles and aggregates.

60 Analytical methodology and data treatment have been developed in ASAXS and electron tomography to 61 suit to these materials. Even if their principles are significantly different, ASAXS and electron microscopy give information in term of particle and aggregate size in good agreement. Likewise, both ASAXS and electron tomography provide some insight on the aggregate structure and morphology. 
564 These complementary techniques have allowed in particular investigating the effect of the reduction step on the particles and on the aggregates. We have shown that the reduction had a slight effect on the particles, decreasing their mean size due to the crystallographic phase transformation from $\mathrm{Co}_{3} \mathrm{O}_{4}$ to $\mathrm{Co}^{0}$, but no phenomenon such as sintering has been observed. To the contrary, we have underlined that the reduction has a significant effect on the aggregates of which morphology, size and structure are certainly defined during the drying and calcination steps. The dense structure with few closed pores of the oxide aggregates evolved into a polycrystalline, porous and airy structure. The porosity of the aggregates is doubled which has the effect to increase drastically the dispersion inside the aggregates and thus increase the number of accessible metallic cobalt active sites. Fischer-Tropsch catalysts activity and selectivity are known to be sensitive to the number and the proximity of the active sites hence the aggregate structure and porosity seem to be important parameters. The operating reduction conditions such as the gas hourly space velocity or the temperature ramp are suspected to affect the internal thermal stresses and thus the final aggregate structure and should be specifically investigated in order to try to improve the catalytic properties.

Finally, as the reduction step has obviously a strong effect on the morphology, the structure and the dispersion of the active phase, it appears clearly that the catalysts have to be characterize in their reduced state in order to explain the catalytic performances. Moreover, it should be even more appropriate to characterize the used catalyst after the catalytic test as the active phase and specially the aggregate structure is potentially affected under Fischer-Tropsch conditions [45]. In this goal, the ASAXS technique should be well suitable as it allows to characterize the particles and the aggregates simultaneously, but especially on catalyst embedded in waxes produced by the synthesis and thus without carrying out a specific washing apt to modify the sample.

This study opens prospects for understanding the role of the carrier chemical and textural properties on the cobalt phase dispersion, but also the role of each drying, calcination and reduction unitary step on particle and aggregates size distributions and cobalt phase dispersion, both parameters that control the active sites number and proximity and thus the activity and the selectivity. Hence, confronting particles

\section{Acknowledgements}

593 Electron tomography acquisitions were partially performed at «Centre Technologique des 594 Microstructures de l'Université Lyon I». The authors thank X. Jaurand for his support. 


\section{References}

597 [1] A.Y. Khodakov, W. Chu, P. Fongarland, Advances in the development of novel cobalt Fischer-

[8] P. Munnik, P.E. de Jongh, K.P. de Jong, Control and Impact of the Nanoscale Distribution of Supported Cobalt Particles Used in Fischer-Tropsch Catalysis, Journal of the American Chemical Society 136 (2014) 7333-7340.

[9] P. Munnik, N.A. Krans, P.E. de Jongh, K.P. de Jong, Effects of Drying Conditions on the Synthesis of $\mathrm{Co} / \mathrm{SiO} 2$ and $\mathrm{Co} / \mathrm{Al} 2 \mathrm{O} 3$ Fischer-Tropsch Catalysts, ACS Catalysis 4 (2014) 3219-3226.

[10] L. Braconnier, E. Landrivon, I. Clemencon, C. Legens, F. Diehl, Y. Schuurman, How does activation affect the cobalt crystallographic structure? An in situ XRD and magnetic study, Catalysis Today 215 (2013) 18-23.

[11] Ø. Borg, J.C. Walmsley, R. Dehghan, B.S. Tanem, E.A. Blekkan, S. Eri, E. Rytter, A. Holmen, Electron Microscopy Study of $\gamma$-A12O3 Supported Cobalt Fischer-Tropsch Synthesis Catalysts, Catal Lett 126 (2008) 224-230. 
[12] S.W.T. Price, D.J. Martin, A.D. Parsons, W.A. Slawinski, A. Vamvakeros, S.J. Keylock, A.M. Beale, J.F.W. Mosselmans, Chemical imaging of Fischer-Tropsch catalysts under operating conditions, SCIENCE ADVANCES 3 (2017).

[13] H.-G. Haubold, K. Gruenhagen, M. Wagener, H. Jungbluth, H. Heer, A. Pfeil, H. Rongen, G. Brandenberg, R. Moeller, J. Matzerath, P. Hiller, H. Halling, JUSIFA-A new user-dedicated ASAXS beamline for materials science, Rev. Sci. Instrum. 60 (1989) 1943.

[14] H.-G. Haubold, X.H. Wang, ASAXS studies of carbon supported electrocatalysts, Nuclear Instruments and Methods in Physics Research Section B: Beam Interactions with Materials and Atoms 97 (1995) 50-54.

[15] H.-G. Haubold, X.H. Wang, H. Jungbluth, G. Goerigk, W. Schilling, In situ anomalous small-angle $\mathrm{X}$-ray scattering and $\mathrm{X}$-ray absorption near-edge structure investigation of catalyst structures and reactions, Journal of Molecular Structure 383 (1996) 283-289.

[16] H.G. Haubold, X.H. Wang, G. Goerigk, W. Schilling, In Situ Anomalous Small-Angle X-ray Scattering Investigation of Carbon-Supported Electrocatalysts, J Appl Crystallogr 30 (1997) 653658.

[17] A. Benedetti, L. Bertoldo, P. Canton, G. Goerigk, F. Pinna, P. Riello, S. Polizzi, ASAXS study of $\mathrm{Au}, \mathrm{Pd}$ and Pd-Au catalysts supported on active carbon, Catalysis Today 49 (1999) 485-489.

[18] A. Benedetti, S. Polizzi, P. Riello, F. Pinna, G. Goerigk, ASAXS Investigation of a Au/C Catalyst, JOURNAL OF CATALYSIS 171 (1997) 345-348.

[19] S. Polizzi, P. Riello, G. Goerigk, A. Benedetti, Quantitative investigations of supported metal catalysts by ASAXS, Journal of synchrotron radiation 9 (2002) 65-70.

[20] G. Beaucage, H.K. Kammler, S.E. Pratsinis, Particle size distributions from small-angle scattering using global scattering functions, J Appl Crystallogr 37 (2004) 523-535.

[21] P.A. Midgley, M. Weyland, 3D electron microscopy in the physical sciences: the development of Zcontrast and EFTEM tomography, Ultramicroscopy 96 (2003) 413-431.

[22] O. Ersen, I. Florea, C. Hirlimann, C. Pham-Huu, Exploring nanomaterials with 3D electron microscopy, Materials Today 18 (2015) 395-408.

[23] O. Ersen, C. Hirlimann, M. Drillon, J. Werckmann, F. Tihay, C. Pham-Huu, C. Crucifix, P. Schultz, 3D-TEM characterization of nanometric objects, Solid State Sciences 9 (2007) 1088-1098.

[24] A.H. Janssen, Van Der Voort, Pascal, A.J. Koster, de Jong, Krijn P., A 3D-TEM study of the shape of mesopores in SBA-15 and modified SBA-15 materialsElectronic supplementary information (ESI) available: Fig. S1: schematic view of the MCM-41 formation mechanism. Movie S2: Aligned TEM tilt series of the SBA-15 particle from Fig. 1 (sample with the lower TEOS to template ratio). Movie 
S3: Aligned TEM tilt series of the SBA-15 particle from Fig. 3 (sample with the higher TEOS to template ratio). See http://www.rsc.org/suppdata/cc/b2/b204943k, Chem. Commun. (2002) 16321633.

663

[25] A.H. Janssen, A.J. Koster, de Jong, Krijn P., Three-Dimensional Transmission Electron Microscopic Observations of Mesopores in Dealuminated Zeolite Y, Angewandte Chemie International Edition 40 (2001) 1102-1104.

[26] de Jong, Krijn P, J. Zečević, H. Friedrich, de Jongh, Petra E, M. Bulut, S. van Donk, R. Kenmogne, A. Finiels, V. Hulea, F. Fajula, Zeolite Y crystals with trimodal porosity as ideal hydrocracking catalysts, Angewandte Chemie (International ed. in English) 49 (2010) 10074-10078.

[27] J. Zečević, C.J. Gommes, H. Friedrich, de Jongh, Petra E, de Jong, Krijn P, Mesoporosity of zeolite Y: quantitative three-dimensional study by image analysis of electron tomograms, Angewandte Chemie (International ed. in English) 51 (2012) 4213-4217.

[28] J. Kenvin, S. Mitchell, M. Sterling, R. Warringham, T.C. Keller, P. Crivelli, J. Jagiello, J. PérezRamírez, Quantifying the Complex Pore Architecture of Hierarchical Faujasite Zeolites and the Impact on Diffusion, Adv. Funct. Mater. 26 (2016) 5621-5630.

[29] J. Zečević, van der Eerden, Ad M.J., H. Friedrich, de Jongh, Petra E., de Jong, Krijn P., H2PtCl6derived Pt nanoparticles on USY zeolite: A qualitative and quantitative electron tomography study, Microporous and Mesoporous Materials 164 (2012) 99-103.

[30] J. Zečević, van der Eerden, Ad M J, H. Friedrich, de Jongh, Petra E, de Jong, Krijn P, Heterogeneities of the nanostructure of platinum/zeolite y catalysts revealed by electron tomography, ACS nano 7 (2013) 3698-3705.

[31] L. Roiban, O. Ersen, C. Hirlimann, M. Drillon, A. Chaumonnot, L. Lemaitre, A.-S. Gay, L. Sorbier, Three-Dimensional Analytical Surface Quantification of Heterogeneous Silica-Alumina Catalyst Supports, ChemCatChem (2016) n/a-n/a.

[32] M.H. Gass, K.K.K. Koziol, A.H. Windle, P.A. Midgley, Four-dimensional spectral tomography of carbonaceous nanocomposites, Nano letters 6 (2006) 376-379.

[33] J.C. Hernández-Garrido, K. Yoshida, P.L. Gai, E.D. Boyes, C.H. Christensen, P.A. Midgley, The location of gold nanoparticles on titania, Catalysis Today 160 (2011) 165-169.

[34] P.D. Nellist, M.F. Chisholm, A.R. Lupini, A. Borisevich, W.H. Sides, S.J. Pennycook, N. Dellby, R. Keyse, O.L. Krivanek, M.F. Murfitt, Z.S. Szilagyi, Aberration-corrected STEM, J. Phys.: Conf. Ser. $26(2006) 7-12$. 
691 [35] I. Arslan, J.C. Walmsley, E. Rytter, E. Bergene, P.A. Midgley, Toward three-dimensional nanoengineering of heterogeneous catalysts, Journal of the American Chemical Society 130 (2008) 5716-5719.

[36] C.J. Gommes, G. Prieto, J. Zecevic, M. Vanhalle, B. Goderis, K.P. de Jong, P.E. de Jongh, Mesoscale Characterization of Nanoparticles Distribution Using X-ray Scattering, ANGEWANDTE CHEMIE-INTERNATIONAL EDITION 54 (2015) 11804-11808.

[37] J.R. Kremer, D.N. Mastronarde, J.R. McIntosh, Computer visualization of three-dimensional image data using IMOD, Journal of Structural Biology 116 (1996) 71-76.

[38] D.N. Mastronarde, Dual-axis tomography: an approach with alignment methods that preserve resolution, Journal of Structural Biology 120 (1997) 343-352.

[39] M. Moreaud, F. Cokelaer, FLOWING BILATERAL FILTER: DEFINITION AND IMPLEMENTATIONS, Image Anal Stereol 34 (2015) 101.

[40] C.T. Chantler, Theoretical Form Factor, Attenuation, and Scattering Tabulation for Z=1-92 from $\mathrm{E}=1-10 \mathrm{eV}$ to $\mathrm{E}=0.4-1.0 \mathrm{MeV}$, Journal of Physical and Chemical Reference Data 24 (1995) 71-643.

[41] C.T. Chantler, Detailed Tabulation of Atomic Form Factors, Photoelectric Absorption and Scattering Cross Section, and Mass Attenuation Coefficients in the Vicinity of Absorption Edges in the Soft XRay $(Z=30-36, Z=60-89, E=0.1 \mathrm{keV}-10 \mathrm{keV})$, Addressing Convergence Issues of Earlier Work, J. Phys. Chem. Ref. Data 29 (2000) 597.

[42] T. Binninger, M. Garganourakis, J. Han, A. Patru, E. Fabbri, O. Sereda, R. Kötz, A. Menzel, T.J. Schmidt, Particle-Support Interferences in Small-Angle X-Ray Scattering from Supported-Catalyst Materials, Phys. Rev. Applied 3 (2015).

[43] F. Zhang, J. Ilavsky, G.G. Long, Quintana, John P. G., A.J. Allen, P.R. Jemian, Glassy Carbon as an Absolute Intensity Calibration Standard for Small-Angle Scattering, Metall and Mat Trans A 41 (2010) 1151-1158.

[44] C.S. Forbes, Statistical distributions, 4th ed., Wiley, Hoboken, N.J., 2011.

[45] D. Moodley, On the deactivation of cobalt-based Fischer-Tropsch synthesis catalysts, Technische Universiteit Eindhoven, 2008. 